\title{
Logging and fire regimes alter plant communities
}

\author{
Elle J. Bowd ${ }^{2}$ David B. Lindenmayer, Sam C. Banks, and David P. Blair \\ Fenner School of Environment and Society, The Australian National University, Canberra, Australian Capital Territory 2601 Australia
}

\begin{abstract}
Disturbances are key drivers of plant community composition, structure, and function. Plant functional traits, including life forms and reproductive strategies are critical to the resilience and resistance of plant communities in the event of disturbance. Climate change and increasing anthropogenic disturbance are altering natural disturbance regimes globally. When these regimes shift beyond the adaptive resilience of plant functional traits, local populations and ecosystem functions can become compromised. We tested the influence of multiple disturbances, of varying intensity and frequency, on the composition and abundance of vascular plant communities and their respective functional traits (life forms and reproductive strategies) in the wet sclerophyll, Mountain Ash Eucalyptus regnans forests of southeastern Australia. Specifically, we quantified the effect of the type and number of disturbances (including fires, clearcut logging, and salvage logging) on plant community composition. We found that clearcut and salvage logging and the number of fires significantly influenced plant community composition and functional traits. Specifically, multiple fires resulted in lower populations of species that depend on on-site seeding for persistence. This includes the common tree species Eucalyptus regnans, Pomaderris aspera, and Acacia dealbata. In contrast, clearcut and salvage logged sites supported abundant on-site seeder species. However, species that depend on resprouting by surviving individuals, such as common and keystone "tree ferns" Dicksonia antarctica and Cyathea australis, declined significantly. Our data have important implications for understanding the relationship between altered disturbance regimes and plant communities and the respective effects on ecosystem function. In a period of rapid global environmental change, with disturbances predicted to increase and intensify, it is critical to address the impact of altered disturbance regimes on biodiversity.
\end{abstract}

Key words: clearcut logging; disturbance regimes; Eucalyptus regnans; plant functional traits; post-disturbance environment; species composition; wildfire.

\section{INTRODUCTION}

Disturbances are key drivers of the composition and function of ecosystems worldwide (Bowman et al. 2009, Seidl et al. 2014a, Fraver et al. 2017). Fire is a major form of natural disturbance and it can influence many ecological patterns and processes including biogeochemical cycles, climate, plant composition, and functional diversity (Westerling and Bryant 2008, Bowman et al. 2009, 2011, Sitters et al. 2016).

Species are adapted to specific fire and disturbance regimes that occur within ecosystems (Keeley 2009, Seidl et al. 2014a). When these regimes exhibit novel intensities and frequencies of disturbance events, or are altered beyond adaptive mechanisms, several key properties can be compromised including (1) resilience (the ability of an ecosystem to return to its original, pre-disturbance, state post-disturbance) and (2) resistance (the ability of an ecosystem to maintain its original, pre-disturbance, state in the face of disturbance). Changes to these properties can fundamentally modify the environmental conditions required for habitat suitability and species persistence (Diaz and Cabido 2001, Cochrane and Laurance 2008, Bowman et al. 2009, Siedl et al. 2014b, Lindenmayer et al. 2016).

In recent decades, large-scale, high-severity fires and anthropogenic disturbances have increased across terrestrial ecosystems worldwide (Hooper et al. 2005, Cochrane and Laurance 2008, Bowman et al. 2009, Seidl et al. 2014a,

Manuscript received 10 October 2017; revised 28 December 2017; accepted 16 January 2018. Corresponding Editor: Bradford P. Wilcox.

${ }^{2}$ E-mail: elle.bowd@anu.edu.au
Lindenmayer et al. 2017). Key examples include the impacts of novel fire regimes and logging that now characterize disturbance patterns in the Pacific northwestern forests of the United States (Odion et al. 2004, Thompson et al. 2007), Amazonian rainforests (Cochrane and Laurance 2008), and southeastern Australian wet sclerophyll forests (Lindenmayer et al. 2011, Taylor et al. 2014). Changing climatic conditions are predicted to increase dry and hot conditions in many parts of the world, which would amplify and further alter these disturbance regimes (Seidl et al. 2014a, Thom and Siedl 2016). In a period of rapid global environmental change, it is critical to examine the impact of changing disturbance regimes on biodiversity (Bowman et al. 2011).

Plant populations are influenced by climate (Levine and Rees 2004, Westerling and Bryant 2008), natural disturbance (Lloret and Zedler 2009), human-accelerated environmental change (Likens 1991, Ribeiro-neto et al. 2016), or a combination of these (Lindenmayer et al. 2011). Plant functional traits such as physiological adaptions and reproductive strategies are critical to plant species persistence under the prevailing disturbance regime (McIntyre and Lavorel 1999, Johnstone et al. 2016). These structural and functional traits are an important ecological tool for determining how plant communities respond to disturbance and the respective effect on ecosystem function (Noble and Slatyer 1980, McIntyre and Lavorel 1999, Cornelissen et al. 2003, Sitters et al. 2016). They also can act as surrogates for physiological functional patterns that are often impractical to measure (McIntyre and Lavorel 1999, Diaz and Cabido 2001). Plant communities and natural disturbances such as fire interact and influence the dynamics of one another (Cochrane and 
Laurance 2008). For example, post-disturbance, early seral environments can be more susceptible to high-severity fire, which in turn, increases early-successional fire-prone vegetation and suppresses the return of mature composition and structure (Thompson et al. 2007, Cochrane and Laurance 2008, Taylor et al. 2014). This can drive positive feedback loops leading to increased fire frequency and severity (Thompson et al. 2007, Cochrane and Laurance 2008). It has been proposed that additional disturbances such as clearcut logging (Thompson et al. 2007, Cochrane and Laurance 2008, Lindenmayer et al. 2011) and altered climatic conditions (Westerling and Bryant 2008, Bowman et al. 2009) can intensify these positive feedback loops and shift ecosystems into functionally compromised states (Lindenmayer et al. 2016).

Changes in natural disturbance regimes can alter plant population dynamics and trigger declines in common and keystone species (Walker 1995, Diaz and Cabido 2001, Brigham and Schwartz 2003, Rodrigo et al. 2004, Hooper et al. 2005, Honnay and Jaquemyn 2006, Ribeiro-neto et al. 2016). The implications of these changes can extend beyond individual species and impact ecological function and resilience (Lawton 1994, Walker 1995, Ough and Murphy 2004, Cochrane and Laurance 2008). Determining the response of plant communities to changing disturbance regimes is therefore fundamental for environmental conservation, planning, and management (Pickett and White 1985, Stevens-Rumann and Morgan 2016). While the effects of altered disturbance regimes are described for some ecosystems (Hessburg et al. 2005, Donato et al. 2009), relatively few studies have examined the synergistic effects of altered disturbance regimes on plant communities and their respective functional traits (Thuiller et al. 2004, Bowman et al. 2009, Osazuwa-Peters et al. 2015).

We quantified the disturbance responses of vascular plant communities in southeastern Australian, wet sclerophyll, Mountain Ash Eucalyptus regnans F.Muell. forests. These forests provide an ideal system to address key questions about the response of plant communities to disturbance regimes as they have a well characterized and diverse disturbance history and have been subject to more than 30 years of long-term ecological monitoring (Lindenmayer 2009). To examine plant community responses, we gathered data in forests that had last been burned in 1850, 1939, 1983, and 2009 and also forests that had experienced clearcut logging in 1980-1985 and 2009-2010 and salvage logging in 2009-2010. We quantified plant species richness, abundance, and respective functional traits (life forms and reproductive strategies) in forests subject to these different kinds of disturbance. This enabled us to address two important questions.

What is the effect of the number of fires on plant community composition and functional traits?-Floristic variation within forests can be strongly influenced by fire (Ough and Ross 1992, Rodrigo et al. 2004, Bowman et al. 2009). Fire regimes in Eucalyptus regnans forests are characterized by infrequent, high-intensity fires that historically had a return period of 75-150 yr (McCarthy et al. 1999). We hypothesized that following fire within this fire return period, plant communities would follow the pattern of gradual succession described by the Initial Floristic Composition model (Elger 1954, McCarthy et al. 1999). The model describes shifts in dominant plant communities that are consistent with the initial, natural succession of wet sclerophyll forests (Elger 1954, Noble and Slatyer 1980, Ashton and Attiwill 1994, Pulsford et al. 2016). This can be partially explained by the resilience and availability of dominant plant propagules that persist post-fire (Lindenmayer and Laurance 2016). Additionally, following this model, we predicted species richness would increase with multiple fires (Elger 1954). We made this prediction based on the post-disturbance influx of early successional and ruderal herbaceous species that are largely absent from mature forests (Cochrane and Laurance 2008, Donato et al., 2009, Blair et al. 2016).

We also hypothesized that the composition of plant communities would differ between sites rarely burned (only once since 1850), and frequently burned within a period substantially less than the historical fire return period (e.g., $70 \mathrm{yr}$ ). This was largely because multiple fires within a short period have the potential to alter ecosystem function (Burns et al. 2015). For example, biological legacies such as logs and large dead trees can be lost after multiple fires, subsequently influencing plant spatial dynamics, as forecast from trait-based disturbance models (Noble and Slatyer 1980, Franklin et al. 2000, Siedl et al. 2014b, Mason et al. 2016). Additionally, fire intervals must be sufficient to allow species to develop reproductive propagules. For example, when fire intervals are $<25 \mathrm{yr}$, Eucalyptus regnans fails to attain sexual maturity and is displaced by Acacia species (Adams and Attiwill 1984, Lindenmayer 2009). Therefore, with successive fires in the last $70 \mathrm{yr}$, we predicted the decline of species that are dependent on on-site seeding (low seed dispersal ability), especially those without persistent soil seed banks or rapid maturation.

What is the effect of clearcut and salvage logging on plant communities and functional traits and how does it differ from unlogged sites in similarly aged, burned forest?--Some authors have argued that clearcut logging imitates the postdisturbance environment of high-severity fire (Attiwill 1994). However, empirical evidence suggests this is not the case (Cochrane and Laurance 2008, Lindenmayer et al. 2011, Blair et al. 2016). We hypothesized that sites subject to clearcut logging would support different plant communities compared to similarly aged, unlogged/burned sites. Specifically, we predicted a reduced occurrence of species that are sensitive to mechanical disturbance. These include species that possess resprouting functional traits, such as "tree ferns," midstory "trees," and "ground ferns" that occur in this ecosystem. This is because logging machinery can uproot and cause physical damage to resprouting structures and subsequently expose them to the high intensity, slashburn that occurs after clearcutting (McIntyre and Lavorel 1999, Ough and Murphy 2004, Blair et al. 2016).

We also hypothesized that plant communities within salvage logged sites and sites subject to multiples fires and clearcut logging, would be the most different in comparison to similarly aged clearcut and unlogged/burned sites. This is largely because these sites have experienced two successive, different disturbances relative to sites subject only to fire. Moreover, in the event of salvage logging, burned areas are subject to clearcut logging at a time when natural regeneration is just beginning to occur and young plants are vulnerable to disturbance (Lindenmayer and Ough 2006). Such 
intense disturbances within a relatively short time interval would likely result in the reduction of plant species with particular functional traits such as those with on-site seed and resprouting propagules (McIntyre and Lavorel 1999, Siedl et al. 2014b).

Our study addresses the ecological outcomes of changes in climate (fire) and anthropogenic (logging) disturbance regimes that are also characterizing many other forest ecosystems worldwide.

\section{Methods}

\section{Site description}

We conducted this study in the Eucalyptus regnans forests of the Victorian Central Highlands, $80-100 \mathrm{~km}$ northeast of Melbourne in southeastern Australia (Fig. 1). These forests occur at altitudes ranging from 150 to $1100 \mathrm{~m}$ and experience consistent high rainfall, receiving on average between 600 and $2000 \mathrm{~mm}$ annually (Blair et al. 2016, Keenan and Nitschke 2016). The typical climate of the region is defined by cool summers and mild, humid winters, with occasional periods of snow (Mackey et al. 2002, Burns et al. 2015). However, periodic hot and dry summers and infrequent wildfires also occur and the frequencies of both have increased over time (Commonwealth Scientific and Industrial Research Organisation (CSIRO) 2010, Taylor et al. 2014).

Eucalyptus regnans forests are characterized by tall eucalypt overstory trees, scattered understory trees, broad-leaved shrubs, and a moist ground layer rich in fern species (Ough 2001, Burns et al. 2015). The world's tallest flowering plant, Eucalyptus regnans, dominates these forests. Eucalyptus obliqua LHer. (Messmate), Eucalyptus cypellocarpa LAS. Johnson (Mountain Grey Gum), Eucalyptus viminalis Labill. (Manna Gum), Eucalyptus nitens Deane \& Maiden (Shining Gum), and Eucalyptus delegatensis RT. Baker. (Alpine Ash) may also be present (Flint and Fagg 2007, Victorian State Government, 2014, Burns et al. 2015). Acacia species such as Acacia dealbata Link., Acacia frigescens J. H. Willis, and Acacia obliquinervia Tindale, Contr. dominate the midstory (Adams and Attiwill 1984, Lindenmayer 2009). Common understory species include Correa lawrenceana Hook., Prostanthera lasianthos Labill., Olearia argophylla Labill., Pomaderris aspera Sieber., Coprosma quadrifida Labill., Pimelea axiflora F Muell., Bedfordia arborescens Hochr., and tree ferns Dicksonia antarctica Labill. and Cyathea australis R.Br. (Ough and Murphy 2004, Flint and Fagg 2007, Blair et al. 2016).

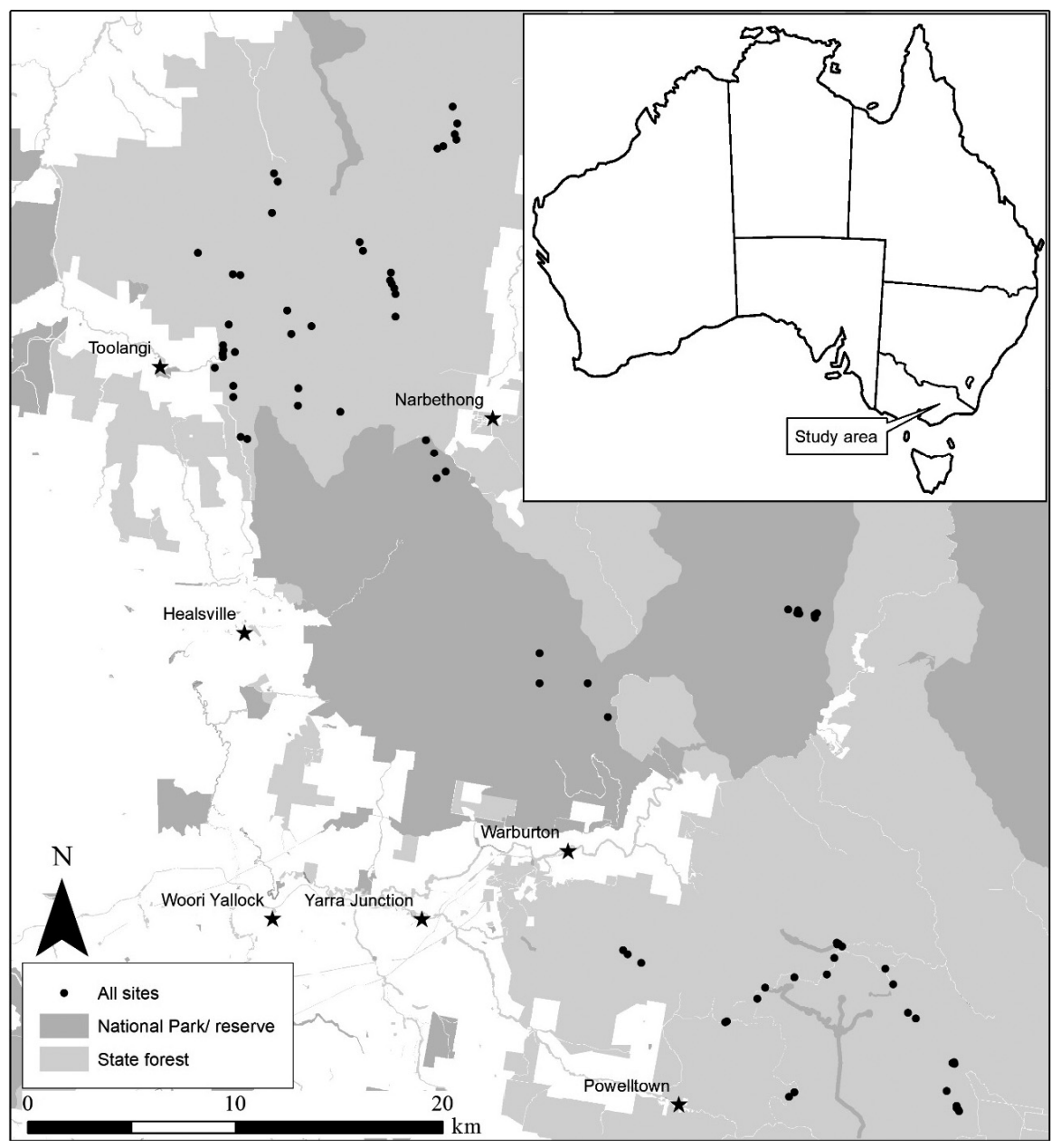

Fig. 1. Location of study sites within the southeastern Victorian Central Highlands in Australia with respect to National Parks and reserves and State forest. 
The edaphic environment of Eucalyptus regnans forests is characterized by well-drained, deep, and nutrient-rich soils that primarily consist of dermosols derived from Ordivian and Devonian sediments, extrusives, granitic rocks, and alluvium (McKenzie et al. 2004, Burns et al. 2015).

\section{Disturbance history}

Approximately 157,000 ha of the Central Highlands support Eucalyptus regnans forests. Of this, 20\% is in closed water catchments and National Parks and $80 \%$ in State forests, which consist of large areas designated for timber and pulp production (Langford 1976, Burns et al. 2015). Large stand-replacing fires in Eucalyptus regnans forests have historically had an average return interval of 75-100 yr (McCarthy et al. 1999). However, over the past century, these forests have experienced major fires in 1926, 1932, 1939, 1983, and most recently in 2009 (Lindenmayer et al. 2011, Turner et al. 2011). In 1939, more than $70 \%$ of these forests were burned and many were subsequently salvage logged until the 1960s (Lindenmayer and Franklin 1997, Lindenmayer and Ough 2006). Because Eucalyptus regnans is an obligate seeder, forests regenerating after large fires, such as those in 1939, have resulted in landscapes with relatively homogenous-aged regrowth (Fig. 2). This dominant age cohort is now the primary resource for the logging industry (Florence 1996, Lutze et al. 1999). The 2009 fires burned 78,300 ha of Eucalyptus regnans forest, with a large proportion of the burned area being the 70-yr-old forest that regenerated after the 1939 fires. The 70-yr-old dead trees resulting from this fire were generally too small to form hollows and the majority of older hollow-bearing trees that pre-dated the fires, were lost (Lindenmayer et al. 2012, Burns et al. 2015). The result has been young, dense, fire-prone regrowth with limited structural diversity (Fig. 3; Lindenmayer et al. 2009, Taylor et al. 2014). Less common, low-intensity fires are not severe enough to kill overstory trees, but trigger a new cohort of regeneration-producing, mixed-age, heterogenous forests (Lindenmayer et al. 1999, Burns et al. 2015).

In the early 1960s, clearcut logging replaced the less intensive, selection logging as the primary silvicultural system in Victorian wet sclerophyll forests (Florence 1996, Lindenmayer et al. 2011, Turner et al. 2011). Clearcutting is a practice where all trees are cut within a block of between 15 and 40 ha (Lutze et al. 1999, Flint and Fagg 2007, Lindenmayer et al. 2011). The remaining debris or slash within a "cutblock" is then burned at high intensity and the cut over area is then aerially seeded with the dominant eucalypt species (Lutze et al. 1999, Flint and Fagg 2007, Lindenmayer et al. 2011). Salvage logging is a form of clearcut logging that occurs usually within three years following high-severity fire (Lindenmayer and Ough 2006, Blair et al. 2016). This practice emulates standard clearcut logging methods, with the exception that there is no slash burn if the regeneration from the initial wildfire is adequate (Blair et al. 2016). In addition, in salvage logging, harvesting occurs after fire, whereas in conventional clearcutting the sequence is reversed. That is, the forest is logged and then subsequently burned.

\section{Study design}

The design of our study was based on the diversity of disturbance histories and the respective availability of replicate sites. We selected nine disturbance types in total: five types experienced fire only and the remaining four types were clearcut or salvage logged. Fire-only sites consisted of forests, long-undisturbed (unburned since 1850), burned once (1939 fire), twice (1939/1983 and 1939/2009), and three times (1939/1983/2009). Logged sites were those burned in 1939 and clearcut in 1980-1985 or 2009-2010 and salvage logged in 2009-2010 after a second fire in 2009. In addition, sites that experienced multiple fires and clearcut logging were those burned in 1939/1983 and clearcut in 2009-2010. All sites were replicated 10 times with the exception of

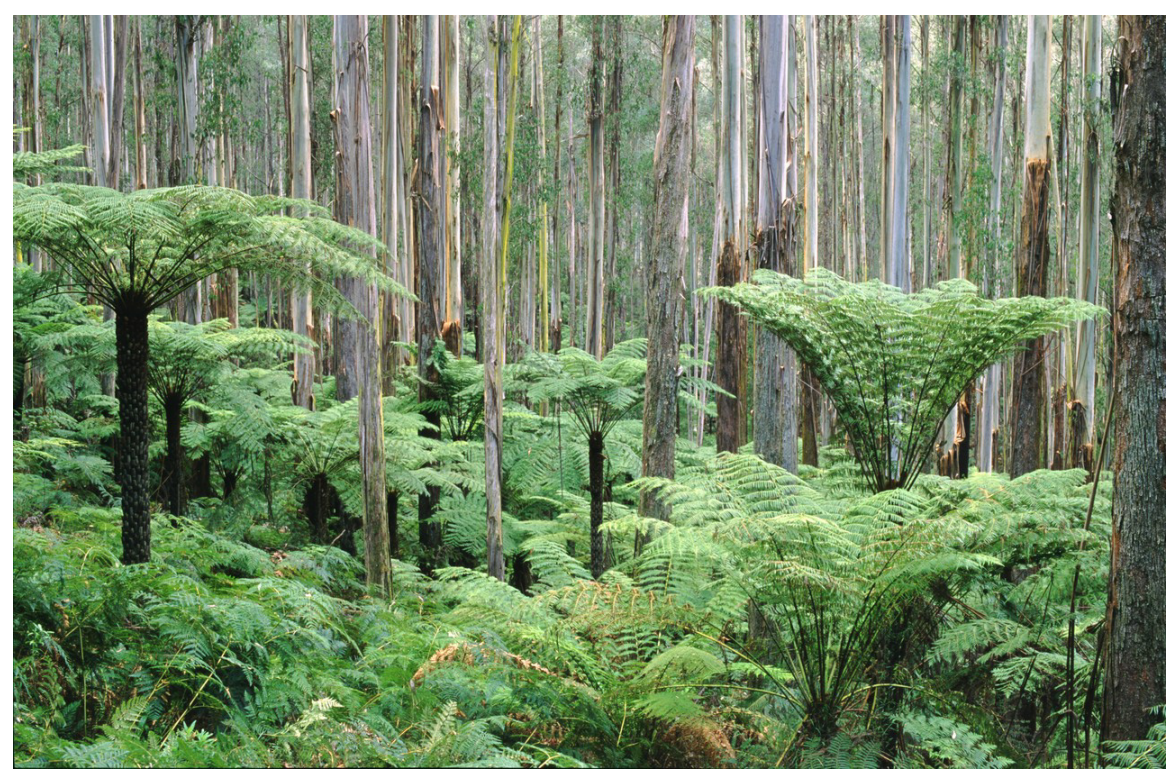

FIG. 2. Eucalyptus regnans forest: 1939 fire regrowth (photographer: David Blair). 


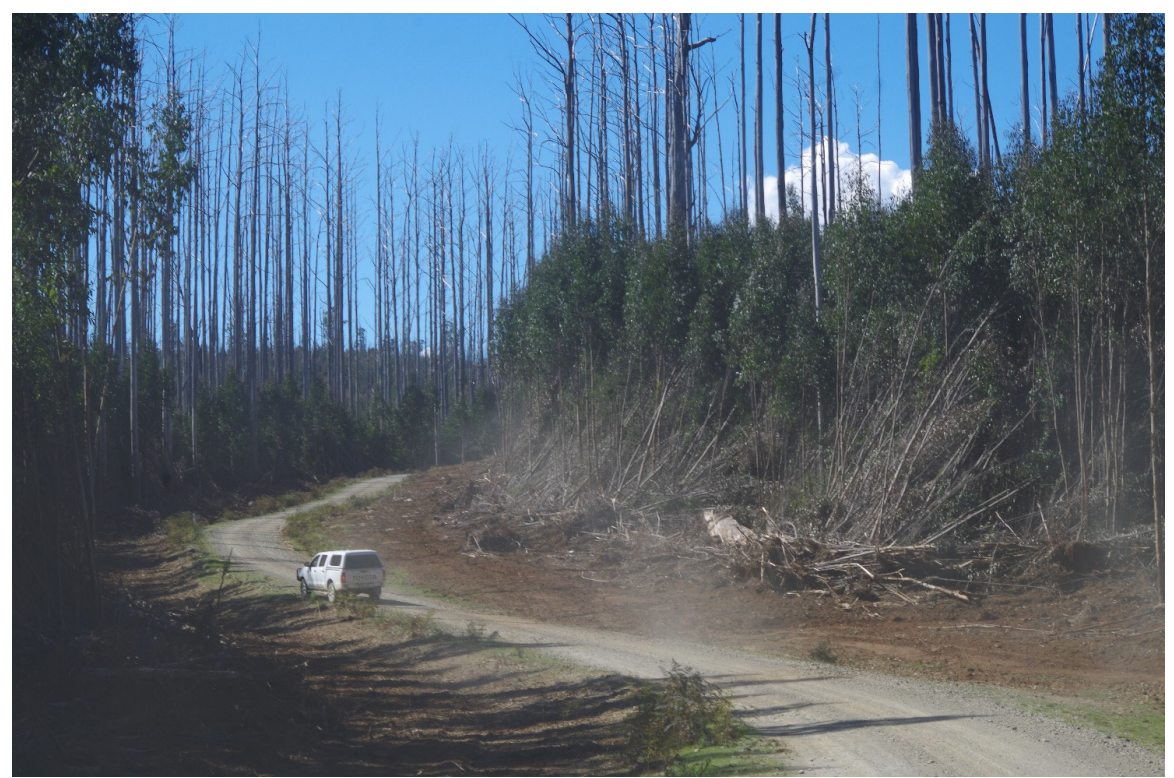

FIG. 3. Eucalyptus regnans forest: 2009 fire and salvage logging regrowth.

forests long-undisturbed (1850), burned twice (1939/2009), and three times (1939/1983/2009; Table 1). All fires were of high severity. However, given the "patchy" nature of fire events, all sites were inspected prior to sampling to ensure consistent age structure, accounting for the potential variability in disturbance severity within each site type. In this study we define "twice-burned" sites as those that had experienced two fires relative to our long-undisturbed sites. This differs from the North American use of "twice burned" that refers to a repeat fire early in succession, which can produce dramatic ecological effects (Fontaine et al. 2009).

Sites were characterized by a southerly aspect and were positioned away from ridges and gullies, which can provide a lot of the variation in disturbance regimes and recovery (Keeton and Franklin 2004).

We sampled all 81 sites during the Australian summer of December 2016-March 2017. Using 1-ha long-term monitoring and newly established plots, we measured quadrats of $25 \times 25 \mathrm{~m}$ at least $20 \mathrm{~m}$ away from the roadside to account for edge effects (Dupuch and Fortin 2013). In each 625- $\mathrm{m}^{2}$ quadrat we estimated the projective foliage cover (percent) of each vascular plant species using the survey protocol and sample configurations developed by the Australian Department of the Environment, Land, Water, and Planning (Victorian State Government, 2004). Projective foliage cover was used as a measure of species abundance, and is hereafter referred to as "abundance."

\section{Defining functional traits}

We assigned all species into one of 11 life forms and one of nine reproductive categories (Appendix S1: Table S1). These categorizations allowed us to examine potential trends in the occurrence and abundance of functional traits as per trait-based disturbance models (Noble and Slatyer 1980, Blair et al. 2016, Sitters et al. 2016). We assigned these categorizations based on field observation and literature reviews (Walsh and Entwisle 1994, 1996, 1997, Costermans 2009, Wood et al. 2010, Bull and Stolfo 2014). Life forms were (1) eucalypts (overstory), (2) Acacia, (3) trees (midstory), (4) shrubs, (5) tree ferns, (6) ground ferns, (7) climbers, (8) graminoids, (9) epiphytes, (10) herbs, and (11)

TABLE 1. The disturbance history and number of replicate sites of each of the nine disturbance types.

\begin{tabular}{|c|c|c|c|c|c|c|c|c|}
\hline Disturbance type & 1850 fire & 1939 fire & 1983 fire & 2009 fire & $\begin{array}{c}1980-1985 \\
\text { clearcut }\end{array}$ & $\begin{array}{c}\text { 2009-2010 } \\
\text { clearcut }\end{array}$ & $\begin{array}{c}2009-2010 \\
\text { salvage }\end{array}$ & $\begin{array}{c}\text { Number } \\
\text { of sites }\end{array}$ \\
\hline $1850 \mathrm{~F}$ & $\mathrm{X}$ & & & & & & & 4 \\
\hline $39 \mathrm{~F}$ & & $X$ & & & & & & 10 \\
\hline $39 / 83 \mathrm{~F}$ & & $\mathrm{X}$ & $\mathrm{X}$ & & & & & 10 \\
\hline $39 / 09 \mathrm{~F}$ & & $\mathrm{X}$ & & $\mathrm{X}$ & & & & 11 \\
\hline $39 / 83 / 09 \mathrm{~F}$ & & $\mathrm{X}$ & $\mathrm{X}$ & $\mathrm{X}$ & & & & 6 \\
\hline $80 \mathrm{CC}$ & & $\mathrm{X}$ & & & $\mathrm{X}$ & & & 10 \\
\hline $09 \mathrm{CC}$ & & $\mathrm{X}$ & & & & $\mathrm{X}$ & & 10 \\
\hline 09SL & & $\mathrm{X}$ & & $\mathrm{X}$ & & & $\mathrm{X}$ & 10 \\
\hline $83 \mathrm{~F} / 09 \mathrm{CC}$ & & $\mathrm{X}$ & $\mathrm{X}$ & & & $\mathrm{X}$ & & 10 \\
\hline
\end{tabular}

Note: F, fire; CC, clearcut; $\mathrm{SL}$, salvage logged. $\mathrm{X}$ in a cell indicates ??? 
exotic (Blair et al. 2016). Tree ferns and ground ferns were categorized into separate groups as tree ferns are structurally a midstory tree, differing in size and function from other fern species and midstory trees (Blair et al. 2016). Additionally, we separated eucalypts and Acacia species from other lifeform groups. This was because eucalypts (trees belonging to the Eucalyptus genus) are the dominant overstory species within these forests, whereas Acacia species dominate the midstory and have different ecological roles, such as nitrogen fixation (Blair et al. 2016). In determining reproductive strategy groups, each species was characterized by their respective temporal dynamics (persistent [longlived] or transitory [species that thrive in post-disturbance environments but do not usually persist beyond several years, otherwise known as ruderal species]) and reproductive mechanisms (wind-dispersed seed, sprout, on-site seed, onsite seed and sprout). These groups were (1) transitory, wind-dispersed seed, (2) transitory, on-site seed, (3) transitory, sprout, (4) persistent, wind-dispersed seed, (5) persistent, on-site seed, (6) persistent, (7) persistent, seed and sprout, (8) persistent, sprout, and (9) exotic. Persistent species were separated from other groups because they are not limited to one reproductive strategy (May and Attiwill 2003, Blair et al. 2016). Exotic species are not specifically a lifeform or reproductive strategy. However, as they are relatively uncommon, and primarily are transitory, herbaceous species such as Cirsium vulgare (Savi.), we grouped them into a separate category.

\section{Statistical analysis}

We evaluated the influence of the number of fires and the effect of clearcut and salvage logging on the composition and abundance of plant communities and respective functional traits (reproductive strategies and life forms) using multivariate permutational analysis of variance (PERMANOVA) based on the Bray-Curtis resemblance matrix of square-root-transformed abundance data (Bray and Curtis 1957, Anderson 2001, Anderson and Walsh 2013). PERMANOVA is routine testing of the simultaneous response of one or more variables to one or more factors in an analysis of variance (ANOVA) based on resemblances between measures using permutation methods (Anderson 2001). All data for each analysis were square-root transformed to minimize the contributions of common taxa with consistently high abundance values (within each group) in relation to those rarer species with consistently lower abundance values (Clarke and Warwick 2001). Significant terms were investigated using a posteriori pair-wise comparisons with the PERMANOVA $t$ statistic (Anderson and Walsh 2013). A maximum of 999 permutations were used to obtain $P$ values in each data set.

Analysis of similarity percentages (SIMPER) allowed us to identify species and functional groups that were responsible for $70 \%$ of the dissimilarity between the number of fires and similarly aged logged and unlogged/burned sites, respectively, as confirmed by the PERMANOVA (Clarke and Warwick 2001).

In determining the effect of the number of fires on the abundance and composition of plant communities and respective functional traits, pairwise tests within each analysis were between fire-only sites: $1850 \mathrm{~F}$ (no fires), $39 \mathrm{~F}$ (one fire), 39/83F (two fires), 39/09F (two fires), and 39/83/09F (three fires). When determining the effect of similarly aged logged and unlogged/burned sites within each analysis, pairwise comparisons were made between sites last burned in 2009 $(39 / 09 \mathrm{~F}, 39 / 83 / 09 \mathrm{~F})$ and those clearcut/salvage logged in 2009-2010 (09CC, 09SL, 83F/09CC) and between sites last burned in 1983 (39/83F) and clearcut in 1980-1985 (80CC).

Additionally, a nonparametric Kruskal-Wallis $H$ test was used to determine differences in species richness between different number of fires, and between similarly aged clearcut and unlogged/burned sites, respectively.

Application of PERMANOVA and SIMPER were conducted in the PRIMER program version 5 and 7 (Primer-E, Plymouth, UK; Clarke 1993, Clarke and Gorley 2015). The Kruskal-Wallace $H$ test was employed using IBM SPSS Statistical software (IBM, SPSS, Armonk, New York, USA).

\section{RESULTS}

\section{Species richness}

We identified 121 species across 81 sites within nine disturbance types (Appendix S1: Table S1). The most speciesrich reproductive functional groups were persistent (31 species total) and persistent, sprout (28 species total) and the most species-rich life forms were herb (31 species total) and shrub (28 species total; Appendix S1: Table S2). Mean species richness differed between the nine disturbance types $(P<0.05)$. Sites burned twice $(39 / 09 \mathrm{~F})$ had the highest mean species richness $(28 \pm 3.6$ species/site [mean $\pm \mathrm{SD}])$, followed by clearcut $(09 \mathrm{CC})$ sites $(27 \pm 8.0)$. Long-undisturbed $(1850 \mathrm{~F})$ sites supported the lowest number of species $(15 \pm 5.2$; Fig. 4).

\section{What is the effect of the number of fires on the abundance and composition of plant communities?}

The number of fires that occurred at each site influenced plant composition and abundance (pseudo $F=4.57$, $P=0.001)$. With the exception of pairwise tests between sites burned once (39F) and twice (39/83F; Average dissimilarity [Av.dis.] $=58.02 ; t=1.20 ; P=0.189)$, the composition and abundance of plant species within all fire-only sites were significantly different from one another $(P<0.05)$. Similarly aged sites burned twice $(39 / 09 \mathrm{~F})$ and three times (39/83/09F), respectively, were significantly different from one another $(P<0.05)$. In addition, sites that were both burned twice, $(39 / 09 \mathrm{~F})$ and $(39 / 83 \mathrm{~F})$, also were significantly different from one another $(P<0.05$; Table 2$)$.

Twenty-two species explained $70 \%$ of the dissimilarity in plant composition and abundance between fire-only sites (Appendix S1: Table S3). Of these species, Olearia argophylla, Pomaderris aspera, Dicksonia antarctica, Eucalyptus regnans, Bedfordia arborescens, Polystichum proliferum R. Br., Cyathea australis, Tetrarrhena juncea $\mathrm{R}$. Br., Blechnum wattsii Tindale, and Correa lawrenceana consistently contributed the most to these differences. The mean abundance of common species Eucalyptus regnans, Dicksonia antarctica, and Blechnum wattsii decreased in sites burned twice (39/83F, 39/09F), and three times $(39 / 83 / 09 \mathrm{~F})$, relative to sites burned once $(39 \mathrm{~F})$. In 


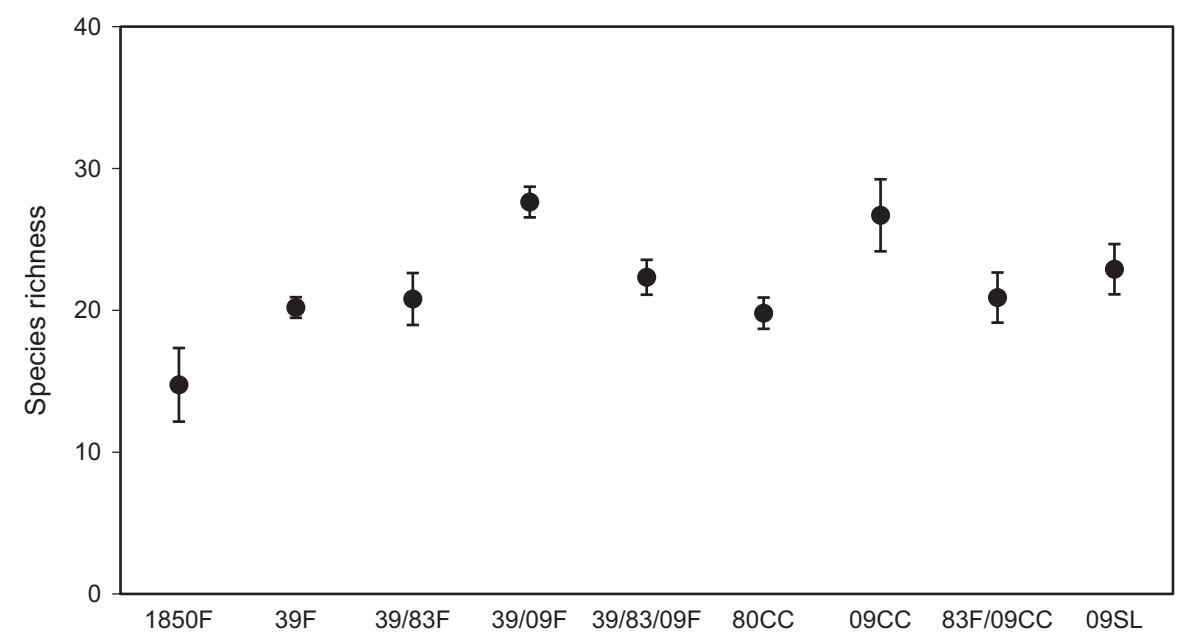

FIG. 4. Species richness across nine disturbance types (mean $\pm \mathrm{SE}$ ). Disturbance types are described in Table 2.

TABLE 2. Main and pairwise tests of multivariate permutational analysis of variance (PERMANOVA) of plant composition and abundance between fire-only sites.

\begin{tabular}{lccc}
\hline \hline Comparison & Dissimilarity (\%) & $T$ & $P$ \\
\hline 1850F (0) vs. 39/83/09F (3) & 66.09 & 2.10 & 0.009 \\
1850F (0) vs. 39/09 F (2) & 76.45 & 2.12 & 0.002 \\
1850F (0) vs. 39F (1) & 65.08 & 1.43 & 0.035 \\
1850F (0) vs. 39/83F (2) & 67.17 & 1.65 & 0.006 \\
39F (1) vs. 39/83/09F (3) & 65.94 & 2.49 & 0.002 \\
39/83F (2) vs. 39/83/09F (3) & 68.12 & 2.74 & 0.001 \\
39/83F (2) vs. 39/09F (2) & 70.4 & 2.45 & 0.001 \\
39/83F (2) vs. 39F (1) & 58.02 & 1.20 & 0.189 \\
39/09F (2) vs. 39F (1) & 71.82 & 2.51 & 0.001 \\
39/09F (2) vs. 39/83/09F (3) & 62.69 & 2.18 & 0.001 \\
\hline
\end{tabular}

Notes: Numbers in brackets in the first column specify the number of fires. Mean dissimilarity is presented. PERMANOVA: pseudo $F=4.57 ; P=0.001$.

contrast, Olearia argophylla, Polystitchum proliferum, and Bedfordia arborescens primarily increased across this comparison. Furthermore, in sites burned three times (39/83/09F), the mean abundance of persistent, on-site-seed species such as Pomaderris aspera and Acacia dealbata decreased, whereas persistent, resprout species such as Olearia argophylla and
Bedfordia arborescens increased in comparison to those burned once (39F; Table 3).

\section{How does the number of fires influence plant functional traits?}

Reproductive strategies. - The composition and abundance of reproductive functional groups differed with the number of fires that occurred at each site (pseudo $F=4.25 ; P=0.001$ ). However, pairwise tests between sites burned once (39F) and twice (39/83F) and between long-undisturbed (1850F) sites and sites burned once (39F) and twice (39/83F and 39/09F) indicated the composition and abundance of these functional groups were not significantly different from one another $(P>0.05$; Table 4). Persistent, on-site seed; persistent, onsite seed and sprout; persistent; persistent, sprout; and persistent, wind-dispersed functional groups explained $70 \%$ of the differences between sites (Appendix S1: Table S4). The 1850F sites supported the highest mean abundance of persistent, sprout and a low mean abundance of persistent, on-site seed species. Sites burned three times (39/83/09F) had the lowest mean abundance of persistent, on-site seed species; persistent; and persistent, on-site seed and sprout species. In contrast, sites burned twice $(39 / 83 \mathrm{~F})$ had the highest mean abundance of persistent, on-site seed and persistent on-site seed and sprout species (Fig. 5).

TABLE 3. Mean abundance of species that consistently contributed to dissimilarity between fire-only sites.

\begin{tabular}{|c|c|c|c|c|c|}
\hline Species & $1850(0)$ & $39 \mathrm{~F}(1)$ & $39 / 83 \mathrm{~F}(2)$ & $39 / 09 \mathrm{~F}(2)$ & $39 / 83 / 09 \mathrm{~F}(3)$ \\
\hline Eucalyptus regnans & 13.4 & 20.13 & 14.63 & 9.07 & 5.88 \\
\hline Olearia argophylla & 5.31 & 2.35 & 1.93 & 9.66 & 11.04 \\
\hline Pomaderris aspera & 0.00 & 2.68 & 12.6 & 13.78 & 0.97 \\
\hline Dicksonia antarctica & 10.94 & 11.23 & 10.14 & 2.66 & 5.8 \\
\hline Blechnum wattsii & 16.06 & 6.63 & 6.28 & 0.02 & 0.00 \\
\hline Tettrarrhena juncea & 7.82 & 8.33 & 3.91 & 8.92 & 0.1 \\
\hline Cyathea australis & 0.19 & 6.32 & 12.58 & 1.63 & 2.74 \\
\hline Polystitchum proliferum & 0.00 & 1.03 & 1.25 & 0.02 & 0.00 \\
\hline Bedfordia arborescens & 0.00 & 0.3 & 1.08 & 4.65 & 9.83 \\
\hline Correa lawrenceana & 1.56 & 5.65 & 14.38 & 0.44 & 0.00 \\
\hline
\end{tabular}

Note: Numbers in brackets in the top row specify the number of fires. 
TABLE 4. Main and pairwise tests of multivariate permutational analysis of variance (PERMANOVA) of the composition and abundance of reproductive strategies between fire-only sites.

\begin{tabular}{lccc}
\hline \hline Comparison & Dissimilarity (\%) & $T$ & $P$ \\
\hline 39/09F (2) vs. 39/83/09F (3) & 33.59 & 2.28 & 0.004 \\
39/09F (2) vs. 39/83F (2) & 33.28 & 2.20 & 0.001 \\
39/09F (2) vs. 1850F (0) & 34.34 & 1.52 & 0.065 \\
39/09F (2) vs. 39F (1) & 33.46 & 2.10 & 0.002 \\
39/83/09F (3) vs. 39/83F (2) & 38.43 & 3.26 & 0.001 \\
39/83/09F (3) vs. 1850F (0) & 32.50 & 1.69 & 0.03 \\
39/83/09F (3) vs. 39F (1) & 35.46 & 2.75 & 0.001 \\
39/83F (2) vs. 1850F (0) & 32.10 & 1.47 & 0.07 \\
39/83F (2) vs. 39F (1) & 27.32 & 1.24 & 0.178 \\
1850F (0) vs. 39F (1) & 32.71 & 1.44 & 0.086 \\
\hline
\end{tabular}

Notes: Numbers in brackets specify the number of fires. Mean dissimilarity is presented. PERMANOVA: pseudo $F=4.25 ; P=0.001$.

Life forms. - The composition and abundance of life forms differed with the number of fires that occurred at each site (pseudo $F=2.91 ; P=0.001$ ). However, the composition and abundance of life forms in long-undisturbed (1850F) sites did not significantly differ from other fire-only sites $(P>0.05)$. Furthermore, sites burned once (39F) and twice $(39 / 83 F)$ were also not significantly different from one another (Table 5). Tree, Acacia, ground fern, eucalypt, graminoid, shrub, and tree fern species explained $70 \%$ of the dissimilarity between sites (Appendix S1: Table S5). Longundisturbed $(1850 \mathrm{~F})$ sites had the lowest mean abundance of life forms, Acacia and shrub species, but had a high mean abundance of ground ferns and trees. Sites burned once $(39 \mathrm{~F})$ and twice $(39 / 83 \mathrm{~F})$ had the greatest mean abundance of tree ferns, Acacia and eucalypt life forms. In contrast, sites burned three times (39/83/09F) had a low mean abundance of eucalypt, Acacia, and graminoid species. Herb and graminoid species were the most abundant in sites burned twice (39/09F; Fig. 6). Epiphytes were the most abundant in long-undisturbed (1850F) sites.
TABLE 5. Main and pairwise tests of multivariate permutational analysis of variance (PERMANOVA) of the composition and abundance of life forms between fire-only sites.

\begin{tabular}{lccc}
\hline \hline Comparison & Dissimilarity (\%) & $t$ & $P$ \\
\hline 39/09F (2) vs. 39/83/09F (3) & 34.74 & 1.89 & 0.004 \\
39/09F (2) vs. 39/83F (2) & 37.61 & 2.07 & 0.001 \\
39/09F (2) vs. 1850F (0) & 41.73 & 1.46 & 0.063 \\
39/09F (2) vs. 39F (1) & 38.35 & 2.0 & 0.001 \\
39/83/09F (3) vs. 39/83F (2) & 36 & 2.55 & 0.001 \\
39/83/09 (3) vs. 1850F (0) & 35.81 & 1.35 & 0.106 \\
39/83/09 (3) vs. 39F (1) & 33.16 & 1.95 & 0.001 \\
39/83F (2) vs. 1850F (0) & 36.42 & 1.08 & 0.32 \\
39/83F (2) vs. 39F (1) & 31.45 & 1.02 & 0.377 \\
1850F (0) vs. 39F (1) & 37.24 & 1.03 & 0.372 \\
\hline
\end{tabular}

Notes: Numbers in brackets specify the number of fires. Mean dissimilarity is presented. PERMANOVA: pseudo $F=2.91 ; P=0.001$.

\section{What is the effect of clearcut logging in comparison to similarly aged unloggedlburned forest?}

Plant species composition and abundance differed between similarly aged unlogged/burned and logged sites (pseudo $F=6.59, P=0.001$; Table 6). Salvage logged (09SL) and sites burned three times $(39 / 83 / 09 \mathrm{~F})$ were the most different from one another (Av.dis. $=82.03 ; t=3.93 ; P=0.002$ ). This trend was followed in pairwise tests between clearcut sites (09CC) and sites burned three times (39/83/09F; Av. dis. = $86.57 ; t=3.50 ; P=0.001)$; and sites burned twice and clearcut $(83 \mathrm{~F} / 09 \mathrm{CC})$ and sites burned three times $(39 / 83 / 09 \mathrm{~F}$; Av. dis. $=83.70 ; t=3.35 ; P=0.001)$. Similarly aged sites burned twice $(39 / 83 \mathrm{~F})$ and clearcut $(80 \mathrm{CC})$ had the lowest dissimilarity and $t$ value of all pairwise tests but also differed significantly in species composition and abundance (Av. dis. = 61.57; $t=1.68 ; P=0.003)$.

Twenty-nine species explained $70 \%$ of the dissimilarity in plant composition and abundance between similarly aged logged and unlogged/burned sites (Appendix S1: Table S6).

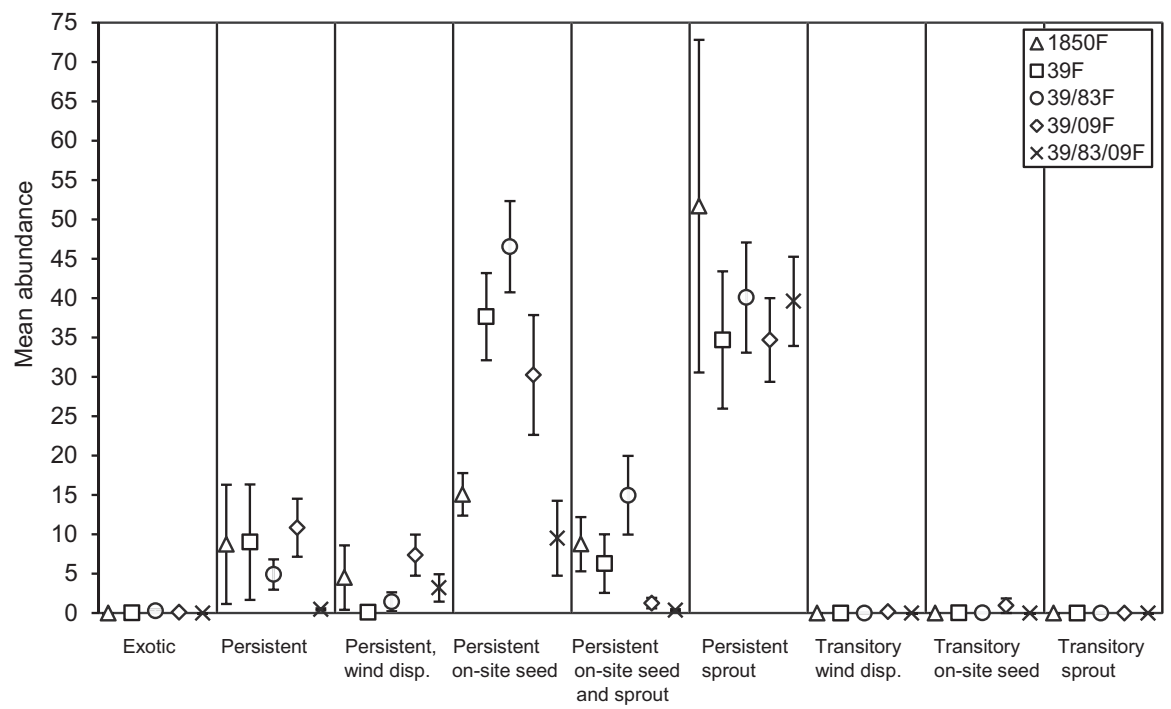

FIG. 5. Abundance of reproductive functional groups across fire-only sites (mean $\pm \mathrm{SE}$ ). 


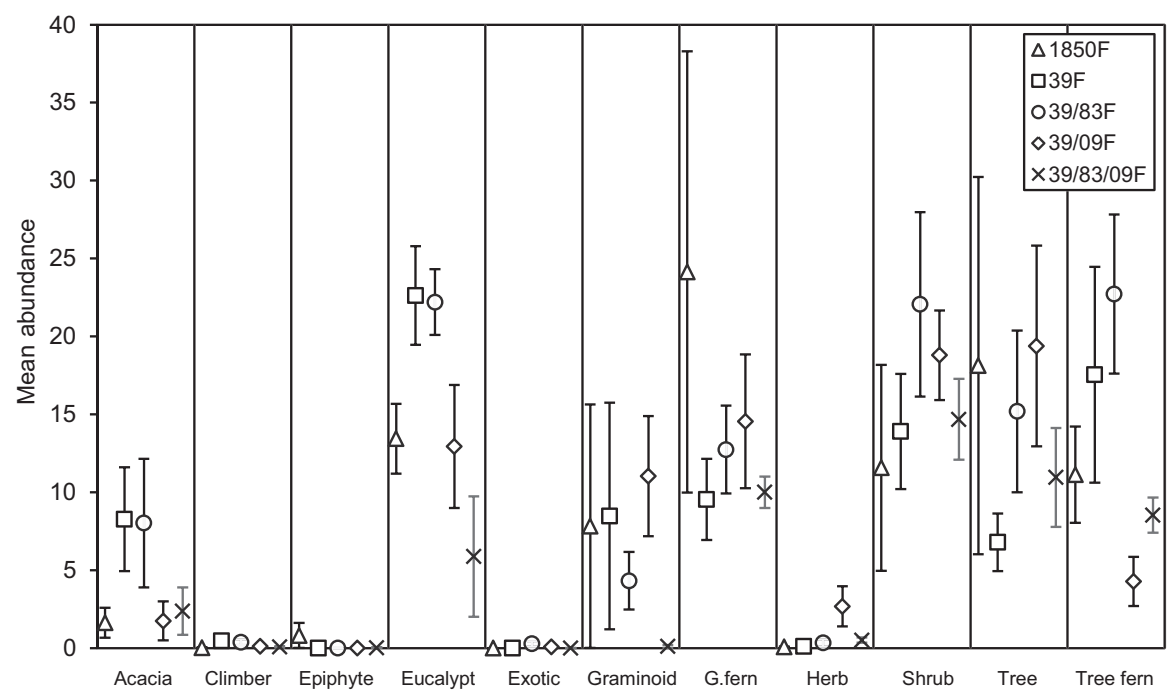

FIG. 6. Abundance of life forms across fire-only sites (mean $\pm \mathrm{SE}$ ). G. fern, ground fern

TABLE 6. Main and pairwise tests of multivariate permutational analysis of variance (PERMANOVA) of vascular plant composition and abundance between similarly aged logged and unlogged/burned sites.

\begin{tabular}{lccc}
\hline \hline Comparison & Dissimilarity (\%) & $t$ & $P$ \\
\hline 39/83F vs. 80CC & 61.57 & 1.68 & 0.003 \\
39/09F vs. 09CC & 73.677 & 2.39 & 0.001 \\
39/09F vs. 39/83/09F & 62.70 & 2.18 & 0.003 \\
83F/09CC vs. 39/09F & 74.45 & 2.49 & 0.001 \\
83F/09CC vs. 39/83/09F & 83.70 & 3.35 & 0.001 \\
83F/09CC vs. 09CC & 70.16 & 1.94 & 0.001 \\
83F/09CC vs. 09SL & 68.28 & 2.26 & 0.001 \\
09CC vs. 39/83/09F & 86.57 & 3.5 & 0.001 \\
09SL vs. 39/83/09F & 82.03 & 3.93 & 0.002 \\
09SL vs. 39/09F & 69.44 & 2.55 & 0.001 \\
09SL vs. 09CC & 65.77 & 2.03 & 0.001 \\
\hline
\end{tabular}

Notes: Mean dissimilarity is presented. PERMANOVA: pseudo $F=6.59 ; P=0.001$

Of these species, Pomaderris aspera, Eucalyptus regnans, Acacia dealbata, Olearia argophylla, Tetrarrhena juncea, Acacia obliquinervia, Polystichum proliferum, Bedfordia arborescens, Pteridium esculatum, and Dicksonia antarctica contributed the most to dissimilarity between site types. Acacia dealbata and Acacia obliquinervia were more abundant in logged sites, whereas persistent, resprout species such as Cyathea australis, Dicksonia antarctica, Olearia argophylla, and Bedfordia arborescens declined in comparison to similarly aged unlogged/ burned sites. Furthermore, salvage logged (09SL) sites supported no common persistent, resprout species: Dicksonia antarctica, Polystichum proliferum, and Olearia argophylla, (Table 7).

\section{How does clearcut logging influence plant functional traits?}

Reproductive strategies. - The mean abundance of reproductive functional groups differed between similarly aged unlogged/burned and logged sites (pseudo $F=8.48 ; P=$ $0.001)$. However, similarly aged logged sites $(83 \mathrm{~F} / 09 \mathrm{CC}$, 09CC, 09SL) and, logged and unlogged/burned sites (80CC, $39 / 83 \mathrm{~F}$ ) were not significantly different from one another $(P>0.05$; Table 8$)$. Persistent, sprout and persistent, on-site seed species were the highest contributors of dissimilarity across pairwise tests between similarly aged logged and unlogged/burned sites (Appendix S1: Table S7). Persistent, resprout species declined and persistent, on-site seed species increased in sites logged in 2009 (83F09CC, 09SL, 09CC),

TABLE 7. Mean abundance of species that consistently contributed to dissimilarity between similarly aged unlogged/burned and logged sites.

\begin{tabular}{|c|c|c|c|c|c|c|c|}
\hline Species & $39 / 83 \mathrm{~F}$ & $80 \mathrm{CC}$ & $39 / 09 \mathrm{~F}$ & $39 / 83 / 09 \mathrm{~F}$ & $09 \mathrm{CC}$ & $83 \mathrm{~F} / 09 \mathrm{CC}$ & 09SL \\
\hline Eucalyptus regnans & 14.6 & 12.4 & 9.1 & 5.9 & 3.3 & 16.9 & 32.0 \\
\hline Pomaderris aspera & 12.6 & 1.9 & 13.8 & 1.0 & 8.6 & 22.8 & 2.5 \\
\hline Acacia dealbata & 3.6 & 12.7 & 1.5 & 0.0 & 25.0 & 8.8 & 10.3 \\
\hline Tetrarrhena juncea & 3.9 & 2.0 & 8.9 & 0.1 & 17.1 & 10.2 & 7.7 \\
\hline Polystichum proliferum & 5.5 & 13.5 & 2.4 & 9.1 & 0.3 & 0.0 & 0.0 \\
\hline Dicksonia antarctica & 10.1 & 7.7 & 2.7 & 5.8 & 0.2 & 0.7 & 0.0 \\
\hline Olearia argophylla & 1.9 & 1.4 & 9.7 & 11.0 & 0.1 & 0.1 & 0.0 \\
\hline Bedfordia arborescens & 1.08 & 0.0 & 4.6 & 9.83 & 0.0 & 0.0 & 0.13 \\
\hline Acacia obliquinervia & 0.15 & 1.73 & 0.00 & 0.00 & 17.34 & 0.00 & 11.98 \\
\hline Pteridium esculatum & 0.21 & 0.27 & 11.2 & 0.3 & 0.8 & 0.08 & 6.53 \\
\hline
\end{tabular}


TABLE 8. Main and pairwise tests of multivariate permutational analysis of variance (PERMANOVA) of the composition and abundance of reproductive functional groups between similarly aged logged and unlogged/burned sites.

\begin{tabular}{lccc}
\hline \hline Comparison & Dissimilarity $(\%)$ & $t$ & $P$ \\
\hline 39/09F vs. 09CC & 41.63 & 2.74 & 0.001 \\
39/09F vs. 39/83/09F & 33.58 & 2.28 & 0.004 \\
39/09F vs. 83F/09CC & 40.43 & 3.5 & 0.001 \\
39/09F vs. 09SL & 35.5 & 3.05 & 0.001 \\
09CC vs. 39/83/09F & 58.94 & 4.33 & 0.001 \\
09CC vs. 83F/09CC & 29.0 & 1.00 & 0.424 \\
09CC vs. 09SL & 29.44 & 1.25 & 0.155 \\
39/83/09 vs. 83F/09CC & 57.05 & 5.53 & 0.001 \\
83F/09CC vs. 09SL & 49.03 & 1.27 & 0.199 \\
80CC vs. 39/83F & 29.03 & 1.04 & 0.338 \\
39/83/09F vs. 09SL & 25.20 & 5.05 & 0.001 \\
\hline
\end{tabular}

Notes: Mean dissimilarity is presented. PERMANOVA: pseudo $F=8.48 ; P=0.001$.

relative to unlogged sites burned in 2009 (39/09F, 39/83/09; Figs 7 and 8).

Life forms. - The composition and abundance of life forms differed significantly between similarly aged logged and unlogged/burned sites (pseudo $F=7.88 ; P=0.001$ ). However, similarly aged logged sites $(83 \mathrm{~F} / 09 \mathrm{CC}, 09 \mathrm{CC})$ were not significantly different from one another $(P>0.05)$. Acacia, ground fern, tree fern, tree, eucalypt, shrub, and graminoid life forms contributed to $70 \%$ of the dissimilarity between sites (Appendix S1: Table S8). Acacia species were more abundant in clearcut and salvage logged sites in comparison to similarly aged unlogged/burned sites. With the exception of sites clearcut in 1980-1985 (80CC), sites clearcut in 2009 (09CC, 09SL, 83F/09CC) supported a lower mean abundance of tree ferns and ground ferns than similarly aged unlogged/burned forest. Salvage logged sites had the highest abundance of herb and eucalypt life forms. Sites logged in 2009-2010 (09CC) had the greatest abundance of Acacia species and the least of eucalypt species in comparison to other sites (Fig. 9).

TABLE 9. Main and pairwise tests of multivariate permutational analysis of variance (PERMANOVA) of lifeform composition and abundance between similarly aged logged and unlogged/ burned sites.

\begin{tabular}{lccc}
\hline \hline Comparison & Dissimilarity (\%) & $t$ & $P$ \\
\hline 39/83F vs. 80CC & 39 & 2.42 & 0.002 \\
39/09F vs. 09CC & 51.35 & 3.18 & 0.001 \\
39/09F vs. 39/83/09F & 34.74 & 1.89 & 0.002 \\
09CC vs. 39/83/09F & 57.21 & 3.82 & 0.001 \\
83F/09CC vs. 39/83/09F & 55.99 & 3.59 & 0.001 \\
83F/09CC vs. 09SL & 41.80 & 1.78 & 0.015 \\
83F/09CC vs. 09CC & 42.55 & 1.60 & 0.051 \\
83F/09CC vs. 39/09F & 47.48 & 2.60 & 0.001 \\
09SL vs. 39/09F & 47.88 & 3.15 & 0.001 \\
09SL vs. 39/83/09F & 54.91 & 4.14 & 0.001 \\
09SL vs. 09CC & 45.50 & 2.37 & 0.001 \\
\hline
\end{tabular}

Notes: Mean dissimilarity is presented. PERMANOVA: pseudo $F=7.88 ; P=0.001$

\section{DisCUSSION}

The relationship between disturbance and the composition of plant communities is often dynamic and complex (McIntyre and Lavorel 1999, Pulsford et al. 2016). Many plant species are highly tolerant of disturbance and are adapted to specific disturbance intensities and frequencies owing their resilience to functional traits such as physiological adaptions and reproductive strategies (McIntyre and Lavorel 1999, Diaz and Cabido 2001, Johnstone et al. 2016). However, when the frequency, type, or severity of disturbance shifts outside the capacity of the functional traits of local species, plant community composition and structure can be altered (Thompson et al. 2007, Cochrane and Laurance 2008, Blair et al. 2016, Stevens-Rumann and Morgan 2016). We found that clearcut and salvage logging and the respective number of fires influenced plant community composition, abundance, and functional traits in the southeastern Australian, Eucalyptus regnans forests. Specifically, species that produce and regenerate from on-site seed decreased with multiple fires and increased with clearcut and salvage logging (in 2009-2010). Whereas species that resprout declined significantly in sites subject to clearcut and salvage logging (in 2009-2010). Our research has important implications for understanding the relationship between altered disturbance regimes and plant communities and the associated effects on ecosystem function.

All sites, apart from those long-undisturbed, were burned in 1939. Therefore, 1939 regrowth acted as a comparative control in our analysis, whereas long-undisturbed forest acted as a reference and contributed to our understanding of succession in Eucalyptus regnans forests. Furthermore, in the analysis of clearcut and salvaged logged sites, similarly aged sites were compared to one another to account for successional effects (Kayes et al. 2010). One constraint of this study is it did not examine the difference between low and high fire severities, which could potentially explain some of the variation in plant community composition within sites (Blair et al. 2016).

\section{The number of fires and plant community composition}

We have demonstrated that the number of fires influenced the composition and abundance of plant communities and their respective functional traits. Consistent with our predictions, plant community composition and abundance in long-undisturbed sites was the most similar to sites burned once in 1939 and followed the pattern of gradual succession described by the Initial Floristic Composition Model (Elger 1954). Furthermore, following the model, species richness was the lowest in long-undisturbed sites and highest in sites burned twice, in 1939 and 2009. This can be explained by an increase in disturbance-adapted graminoid and herbaceous species, and the ground fern Pteridium esculatum post-disturbance in response to an influx in available resources and reduced competition (Kayes et al. 2010, Blair et al. 2016).

In contrast, the composition and abundance of plant communities in eight-year-old forests burned twice and three times differed from other sites and from one another. This indicates that, while succession (time since the most recent fire) is a major factor in determining plant community composition, the number of fires is also a key contributor, 


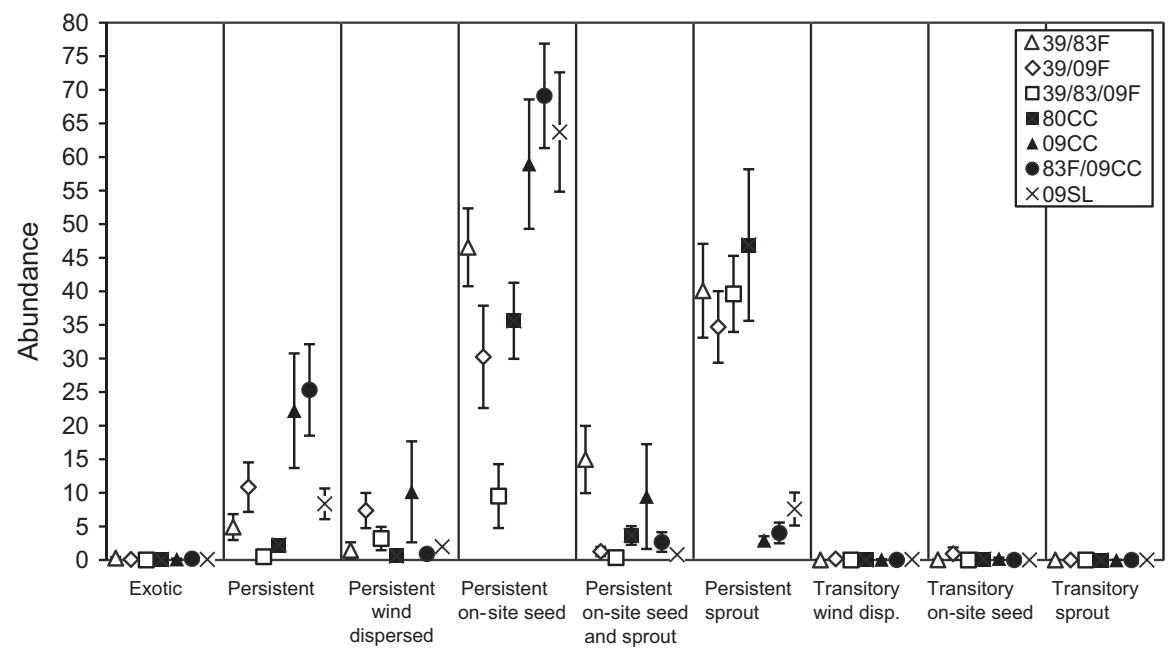

FIG. 7. Abundance of the most common functional groups across logged and unlogged/burned sites (mean \pm SE). Open shapes indicate unlogged/burned sites and solid shapes indicate logged sites.

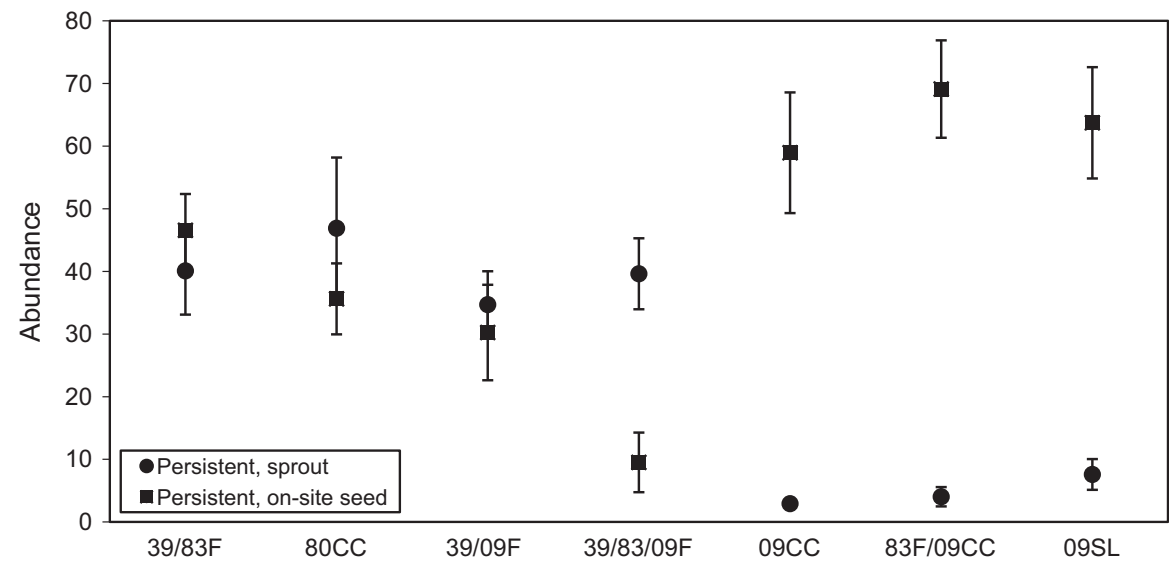

FIG. 8. Abundance of persistent on-site seed and persistent sprout functional groups across similarly aged logged and unlogged/burned sites (mean $\pm \mathrm{SE}$ ).

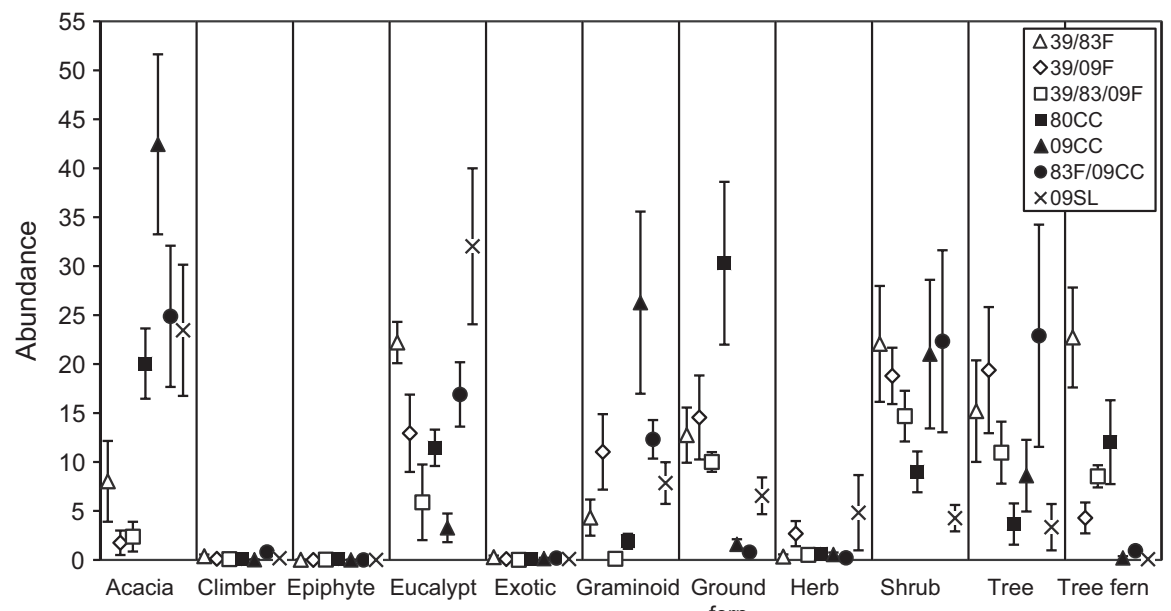

FIG. 9. Abundance of life forms across similarly aged logged and unlogged/burned sites (mean $\pm \mathrm{SE}$ ). Open shapes indicate unlogged/ burned sites, solid shapes indicate logged sites, $x$ is salvage logged sites. 
especially in the event of multiple fires. Similarly, North American forests (Thompson et al. 2007, Stevens-Rumann and Morgan 2016) and Amazonian forests (Cochrane and Laurance 2008) have experienced changes in vegetation community structure and abundance after successive fires. These changes in vegetation communities can alter fire regimes and the risk of high-severity fire in a variety of ways (Thompson et al. 2007, Cochrane and Laurance 2008, Stevens-Rumann and Morgan 2016).

Consistent with our prediction at the outset of this investigation, the composition and abundance of plant functional traits, particularly reproductive strategies, were influenced by the number of fires. The most obvious trends were in eight-year-old forests burned twice and three times, respectively, where we observed declines in dominant on-site seeder species, Eucalyptus regnans, and resprouting tree ferns Cyathea australis and Dicksonia antarctica. However, sites burned three times had a higher abundance of other resprouting species, including Olearia argophylla, Bedfordia arborescens, and Polyschitum proliferum, relative to other sites. This reflects the resilience of resprouting reproductive propagules to fire, as found in North American forests (Donato et al. 2009, Lindenmayer and Laurance 2016). In contrast, sites burned three times had the lowest mean abundance of on-site seeder species, which translated to a decline in common species, Eucalyptus regnans, Pomaderris aspera, and Acacia dealbata, and an absence in Correa lawrenceana. On-site seeder species are particularly sensitive to fire return intervals shorter than their maturation ages and this can result in local extinction (Adams and Attiwill 1984, Bowman et al. 2014, Smith et al. 2014). Furthermore, this group of species is vulnerable to recruitment failure and loss of pollinators and dispersers after disturbance (Smith et al. 2014). It is therefore possible that these species declined and were absent as a result of fire return intervals or dispersal failure. However, as this study did not examine the temporal dynamics within each site, or pre-disturbance conditions, it is possible that these species did not previously occupy these sites. It is also possible that nearby populations of these species could re-colonize these sites if conditions are appropriate. Furthermore, in the short-term, it is unlikely that declines in these species would pose serious ecological threats in isolated sites, and may enhance landscape-scale diversity. However, in the long term, the decline of these species lends concern for ecological function, especially in the event of future fire and disturbance.

Plant functional traits, particularly in dominant and common species, confer ecosystem resilience and resistance (Walker 1995, Diaz and Cabido 2001, Johnstone et al. 2016). Declines in these species can have flow on consequences if their functional roles are lost or reduced (Lawton 1994, Walker 1995, Ough and Murphy 2004, Cochrane and Laurance 2008). As an example, the decline and absence of species such as Acacia species can have impacts on ecosystem function. Acacia species are known for their ability to fix nitrogen, which is particularly important post disturbance (May and Attiwill 2003, Ma et al. 2015). Furthermore, declines in common tree species, Eucalyptus regnans, Pomaderris aspera, and Acacia species, can result in a shift in forest structure and dominance, leading to potentially devastating effects on ecosystem function (Elger 1954, Cochrane and Laurance
2008, Lindenmayer et al. 2011). These effects include changes to the availability of food and complex habitat for biodiversity. For example, mature Eucalyptus species develop hollows from $\sim 120+$ years of age that provide for hollow-dependent mammals such as the critically endangered Leadbeater's possum (Gymnobelideus leadbeateri) and the vulnerable Greater glider (Petauroides volans) in Eucalyptus regnans forests (Lindenmayer et al. 2013).

\section{Clearcut logging and plant community composition}

Our study provides evidence that clearcut logging does not mimic the post-disturbance environment of high-severity fire. Forest clearcut, salvage logged in 2009-2010, and similarly aged, unlogged sites burned twice and three times consistently differed from one another. In sites clearcut and salvaged logged in 2009-2010, common and keystone resprouting species including Cyathea australis, Dicksonia antarctica, Olearia argophylla, and Bedfordia arborescens declined significantly, whereas on-site seeder species such as Acacia dealbata increased (Fig. 8). Resprouting species possess resprouting organs (lignotubers, rhizomes, non-woody tubers, etc.) that, while being resilient to fire, are sensitive to the mechanical disturbances associated with clearcut logging (Ough and Murphy 2004, Keith et al. 2007, Blair et al. 2016). Furthermore, earth-moving machinery used in clearcutting operations can compact soil, displace soil seed banks, and kill, damage, and expose resprouting organs (Rab 1996, Ough and Murphy 2004, Wienk and McPherson 2004, Parro et al. 2015). Our findings are consistent with previous research that has identified declines in resprouting species such as tree ferns following logging (Mueck and Peacock 1992, Hickey 1994, Ough 2001, Ough and Murphy 2004, Blair et al. 2016). Ough and Murphy (2004) found only $16 \%$ of 2,391 tree ferns remained alive one year after clearcutting in Australian wet sclerophyll forests with only $5 \%$ remaining upright. Resprouting species, such as tree ferns and broad-leaf shrubs, cast shadows on the forest floor, which influence the microclimate (Wood et al. 2010, Taylor et al. 2014). Furthermore, tree ferns, including Dicksonia antarctica and Cyathea australis, provide substrates for epiphytic species, including rare and vulnerable plant taxa (Ough and Murphy 2004). Changes in the abundance of these species will increase light and the temperatures experienced by the understory, favoring some species over others (Wienk and McPherson 2004, Penman et al. 2008).

The high mean abundance of Eucalyptus regnans in most clearcut and salvage logged sites (in 2009) is most likely to be a result of post-logging aerial seeding (VicForests 2016). However, inconsistent with predictions we made at the outset of this investigation, the relative mean abundance of Eucalyptus regnans was much lower than expected in some recently clearcut sites that were dominated by Acacia species. We suspect re-seeding attempts have failed in some of these sites. If eucalypt stocking rates are not achieved after the initial slash-burn post-logging, "cut-blocks" can be mechanically re-disturbed and re-sewn to ensure a homogenous stand for future timber harvesting (VicForests 2014).

The impacts of clearcut and salvage logging on biological legacies can explain the patterns we observed in plant communities (Lindenmayer et al. 2008). All natural disturbances 
leave behind biological legacies. In the case of plant species, these biological legacies can include live and dead trees, and seeds that facilitate regeneration post-disturbance (Franklin et al. 2000, Lindenmayer et al. 2017). These enhance the recovery and resilience of forest ecosystems (Siedl et al. 2014b). For example, biological legacies provide structural complexity that generates regeneration niches for shade-tolerant species (Keith et al. 2007, Siedl et al. 2014b). However, in the event of clearcut and salvage logging, few of these legacies remain (Lindenmayer et al. 2008, Fraver et al. 2017). Despite a long history of use in forested ecosystems, there is much debate surrounding clearcut and salvage logging practices (Lindenmayer and Ough 2006, Thompson et al. 2007, Lindenmayer et al. 2008, Parro et al. 2015, Blair et al. 2016, Thorn et al. 2017). Salvage logging in some ecosystems has had positive (Boucher et al. 2014) or negative effects (Lindenmayer and Ough 2006, Lindenmayer et al. 2008, Thorn et al. 2017) on long-term forest recovery. In our study, plant composition and abundance differed the most in sites salvage logged and those burned twice and clearcut in comparison to similarly aged unlogged/burned sites. These similarly aged logged sites were characterized by a low mean abundance of resprouting species relative to all other disturbance types. Furthermore, salvage logged sites contained no records of the common species Polystichum proliferum, Olearia argophylla, and Dicksonia antarctica. The lack of biological legacies and subsequent exposure and physical damage caused by logging machinery are thought to have played a major role in the absence of these integral species (Ough and Murphy 2004, Wienk and McPherson 2004). The intensity and lasting impact of these disturbances on microclimatic conditions suggests that it is unlikely that these species will re-occupy these sites in the near future (Ough and Murphy 2004). Similarly, in North American forests, salvage logging has altered plant species composition (Thompson et al. 2007, Parro et al. 2015). Such shifts, especially in common and keystone species, may reduce ecosystem resistance and resilience and can trigger ecosystem collapse and positive feedback loops (Ough and Murphy 2004, Lindenmayer et al. 2011, 2016, Belote et al. 2012).

Previous research in Eucalyptus regnans forests predicted species composition to rapidly return to that of pre-disturbance conditions after logging and fire (Attiwill 1994, Ashton and Martin 1996). However, we found that after eight years, some common and keystone species had still not returned post-clearcut logging. We assume that these plant communities will take many years to recover. Sites clearcut and salvage logged in 2009-2010 were dominated by Acacia and Eucalyptus species and had an understory consisting of species life forms that are more characteristic of drier environments including graminoids, herbs, and shrubs such as Cassinia aculeata Labill. Species and life forms that are more characteristic of wet forest, including tree ferns and broad leaved shrubs and trees, were consistently absent or had low populations following these disturbances, indicating a shift favoring drier and disturbance-tolerant species (Mueck and Peacock 1992, Ough and Murphy 2004, Blair et al. 2016). These changes in plant community composition could potentially influence the flammability and likelihood of high-severity fire during a fire. Therefore, our findings provide evidence of the "landscape trap" theory, whereby successive fires, anthropogenic disturbance, and climate change drive positive feedback loops between vegetation composition, structure, and ecosystem function (Lindenmayer et al. 2011, Hughes et al. 2013). The already changing and intensifying disturbance regimes in North American forests and Amazonian forests could eventually produce similar positive feedback loops (Thompson et al. 2007, Cochrane and Laurance 2008, Bowman et al. 2011, Lindenmayer et al. 2011).

\section{Implications for forest management and conservation}

Our findings have important implications for forest management globally. We have found that plant community composition and abundance and their respective functional traits can be altered by clearcut and salvage logging and multiple fires within a 26-70 yr interval. Similar changes in plant communities have occurred in other ecosystems around the world that have been affected by fire and clearcut logging (Thompson et al. 2007, Cochrane and Laurance 2008, Lindenmayer et al. 2009). However, disturbance may sometimes enhance diversity in other landscapes that are subject to multiple disturbances if one disturbance type is not dominant, and historic landscape dynamics are considered (Hessburg, et al., 2005, Donato et al., 2009, Fontaine et al. 2009).

Anthropogenic disturbances and climate change are driving large-scale changes to fire and disturbance regimes, globally (Brotons et al. 2013, Hughes et al. 2013, Siedl et al. 2014b). As such, many ecosystems are thought to be at risk of substantial change or collapse (Sato and Lindenmayer 2017). The greatest challenge in addressing altered disturbance regimes is incorporating them into global governance and management (Hughes et al. 2013). Given the changes in plant community composition as a result of altered disturbance regimes in southeastern Australian Eucalyptus regnans forests, our results suggest land managers take a precautionary approach to ecological management and conservation. Furthermore, in a period of rapid, global, environmental change, with disturbances predicted to increase and intensify, it is critical we mitigate the negative impacts of altered disturbance regimes on biodiversity (Hughes et al. 2013). Our data indicates major interventions are needed in policy and land management practices to manage the threats associated with altered disturbance regimes (Bowman et al. 2011, Siedl et al. 2014b). These include conserving large areas of intact forest $(>1,000 \mathrm{ha})$ and reducing the rates of clearcut logging, particularly in sensitive locations and areas already subjected to prior disturbance (Lindenmayer et al. 2011, Blair et al. 2016). These patches provide invaluable refugia for biodiversity and are fundamental in providing source populations for the recolonization of disturbed sites (Lindenmayer et al. 2011). Furthermore, we urge land managers to reconsider salvage logging operations to retain crucial biological legacies and plant functional traits, which will allow for the natural recovery of post-fire environments. Moreover, there is a need to incorporate the abundance and diversity of plant functional traits into ecosystem assessments and future empirical studies.

\section{ACKNOWLEDGMENTS}

We thank the volunteers who assisted in data collection. Supporting funding was provided by The Australian National University 
and the Paddy Pallin Foundation. We thank the editor Bradford Wilcox and the two anonymous reviewers for their comments, which improved the manuscript.

\section{Literature Cited}

Adams, M. H., and P. M. Attiwill. 1984. The role of Acacia spp. in nutrient balance and cycling in regenerating Eucalyptus regnans F. Muell. forests. I. Temporal changes in biomass and nutrient content. Australian Journal of Botany 32:205-215.

Anderson, M. J. 2001. A new method for non-parametric multivariate analysis of variance. Austral Ecology 26:32-46.

Anderson, M. J., and D. C. I. Walsh. 2013. PERMANOVA, ANOSIM, and the Mantel test in the face of heterogeneous dispersions: What null hypothesis are you testing? Ecological Monographs 83:557-574.

Ashton, D. H., and P. M. Attiwill. 1994. Tall open forests. Pages 157-196 in R. H. Groves, editor. Australian vegetation. Second edition. Cambridge University Press, Cambridge, UK.

Ashton, D. H., and D. Martin. 1996. Regeneration in a pole-stage forest of Eucalyptus regnans subjected to different fire intensities in 1982. Australian Journal of Botany 44:393-410.

Attiwill, P. M. 1994. Ecological disturbance and the conservative management of eucalypt forests in Australia. Forest Ecology and Management 63:301-346.

Belote, R. T., R. H. Jones, and T. F. Wieboldt. 2012. Compositional stability and diversity of vascular plant communities following logging disturbance in Appalachian forests. Ecological Applications 22:502-516.

Blair, D. P., L. M. McBurney, W. Blanchard, S. C. Banks, and D. B. Lindenmayer. 2016. Disturbance gradient shows logging affects plant functional groups more than fire. Ecological Applications 26:2280-2301.

Boucher, D., S. Gauthier, J. Noël, D. F. Greene, and B. Bergeron. 2014. Salvage logging affects early post-fire tree composition in Canadian boreal forest. Forest Ecology and Management 325:118-127.

Bowman, D. M. J. S., et al. 2009. Fire in the earth system. Science 324:481-484.

Bowman, D. M. J. S., et al. 2011. The human dimension of fire regimes on Earth. Journal of Biogeography 38:2223-2236.

Bowman, D. M. J. S., B. P. Murphy, D. L. J. Neyland, G. J. Williamson, and L. D. Prior. 2014. Abrupt fire regime change may cause landscape-wide loss of mature obligate seeder forests. Global Change Biology 20:1008-1015.

Bray, R., and J. T. Curtis. 1957. Ordination of the upland forest communities of Southern Wisconsin. Ecological Monographs 27:325-349.

Brigham, C. A., and M. W. Schwartz. 2003. Population viability in plants: conservation, management, and modelling of rare plants. Springer, New York, New York, USA.

Brotons, L., N. Aquilué, M. Cáceres, M. J. Fortin, and A. Fall 2013. How fire history, fire suppression practices and climate change affect wildfire regimes in Mediterranean landscapes. PLoS ONE 8(5):1-12.

Bull, M., and G. Stolfo. 2014. Flora of Melbourne. CSIRO Publishing, Clayton, Victoria, Australia.

Burns, E. L., D. B. Lindenmayer, J. Stein, J. Blanchard, L. McBurney, D. Blair, and S. C. Banks. 2015. Ecosystem assessment of mountain ash forest in the Central Highlands of Victoria, south-eastern Australia. Austral Ecology 40:386-399.

Clarke, K. R. 1993. Non-parametric multivariate analyses of changes in community structure. Australian Journal of Ecology 18:117-143.

Clarke, K. R., and R. N. Gorley. 2015. PRIMER v7: user manual/tutorial. PRIMER-E, Plymouth, UK.

Clarke, K. R., and R. M. Warwick. 2001. Change in marine communities: an approach to statistical analysis and interpretation. Second edition. PRIMER-E, Plymouth, UK.
Cochrane, M. A., and W. F. Laurance. 2008. Synergisms among fire, land use, and climate change in the amazon. Ambio 37:522-527.

Commonwealth Scientific and Industrial Research Organisation (CSIRO). 2010. Climate variability and change in south-eastern Australia: A synthesis of findings from Phase 1 of the South Eastern Australian Climate Initiative (SEACI). CSIRO, Australia.

Cornelissen, J. H. C., et al. 2003. A handbook of protocols for standardised and easy measurement of plant functional traits worldwide. Australian Journal of Botany 51:335-380.

Costermans, L. 2009. Native trees and shrubs of south-eastern Australia. CSIRO Publishing, Clayton, Victoria, Australia.

Diaz, S., and M. Cabido. 2001. Vive la différence: plant functional diversity matters to ecosystem processes. Trends in Ecology and Evolution 16:646-655.

Dupuch, A., and D. Fortin. 2013. The extent of edge effects increases during post-harvesting forest succession. Biological Conservation 163:9-16.

Elger, F. 1954. Vegetation science concepts I. Initial floristic composition, a factor in old-field vegetation development. Vegetatio 4:412-417.

Flint, A., and P. Fagg. 2007. Mountain Ash in Victoria's State Forests: silviculture reference manual no. 1. State of Victoria, Victorian State Government, Victoria, Australia.

Florence, R. G.. 1996. Ecology and silviculture of eucalypt forests. CSIRO Publishing, Clayton, Victoria, Australia.

Fontaine, J. B., D. C. Donato, W. D. Robinson, B. E. Law, and J. Boone Kauffman. 2009. Bird communities following high-severity fire: Response to single and repeat fire in mixed-evergreen forest, Oregon, USA. Forest Ecology and Management 257:1496-1504.

Franklin, J. F., D. Lindenmayer, J. A. MacMahon, A. McKee, J. Magnuson, D. A. Perry, R. Waide, and D. Foster. 2000. Threads of continuity. Conservation in Practice 1:8-17.

Fraver, S., K. J. Dodds, L. S. Kenefic, R. Morrill, R. S. Seymour, and E. Sypitkowski. 2017. Forest structure following tornado damage and salvage logging in northern Maine, USA. Canadian Journal of Forest Research 47:560-564.

Hickey, J. E. 1994. A floristic comparison of vascular species in Tasmanian old growth mixed forest with regeneration resulting from logging and wildfire. Australian Journal of Botany 42:383-404.

Honnay, O., and H. Jaquemyn. 2006. Susceptibility of common and rare plant species to the genetic consequences of habitat fragmentation. Conservation Biology 21:823-831.

Hooper, D. U. III, et al. 2005. Effects of biodiversity of ecosystem functioning. Ecological Monographs 75:3-35.

Hughes, T. P., S. Carpenter, J. Rockström, M. Scheffer, and B. Walker. 2013. Multiscale regime shifts and planetary boundaries. Trends in Ecology and Evolution 28:389-395.

Johnstone, J. F., et al. 2016. Changing disturbance regimes, ecological memory, and forest resilience. Frontiers in Ecology and the Environment 14:369-378.

Kayes, L. J., P. D. Anderson, and K. J. Puettmann. 2010. Vegetation succession among and within structural layers following wildfire in managed forests. Journal of Vegetation Science 21:233-247.

Keeley, J. E. 2009. Fire intensity, fire severity and burn severity: a brief review and suggested usage. International Journal of Wildland Fire 18:126.

Keenan, R. J., and C. Nitschke. 2016. Forest management options for adaption to climate change: a case study of tall, wet eucalypt forests in Victoria's Central Highlands region. Australian Forestry 79:96-107.

Keeton, W. S., and J. F. Franklin. 2004. Fire-related landform associations of remnant old-growth trees in the southern Washington Cascade Range. Canadian Journal of Forest Research 34:23712381.

Keith, D. A., L. Holman, S. Rodoreda, J. Lemmon, and M. Bedward. 2007. Plant functional types can predict decade-scale changes in fire-prone vegetation. Journal of Ecology 95:1324-1337.

Langford, K. J. 1976. Change in yield of water following a bushfire in a forest of Eucalyptus regnans. Journal of Hydrology 29:87-114. 
Lawton, J. H. 1994. What do species do in ecosystems? Nordic Society Oikos 71:367-374.

Levine, J. M., and M. Rees. 2004. Effects of temporal variability on rare plant persistence in annual systems. American Naturalist $164: 350-363$

Likens, G. 1991. Human-accelerated environmental change. BioScience 4:130.

Lindenmayer, D. B. 2009. Old forest, new perspectives: Insights from the Mountain Ash forests of the Central Highlands of Victoria, south-eastern Australia. Forest Ecology and Management 258 357-365.

Lindenmayer, D. B., D. Blair, L. McBurney, S. C. Banks, J. A. R. Stein, R. J. Hobbs, G. E. Likens, and J. F. Franklin. 2013. Principles and practices for biodiversity conservation and restoration forestry: a 30 year case study on the Victorian montane ash forests and the critically endangered Leadbeater's Possum. Australian Zoologist 36:441-460.

Lindenmayer, D. B., W. Blanchard, L. McBurney, S. Banks, G. E. Likens, J. F. Franklin, W. F. Laurance, J. A. R. Stein, and G. Gibbons. 2012. Interacting factors driving a major loss of trees with cavities in a forest ecosystem. PLoS ONE 7(10):1-16.

Lindenmayer, D. B., P. J. Burton, and J. Franklin. 2008. Salvage logging and its ecological consequences. CSIRO Publishing, Clayton, Victoria, Australia.

Lindenmayer, D. B., and J. F. Franklin. 1997. Managing stand structure as part of ecologically sustainable management in Australian Mountain Ash Forests. Conservation Biology 11:1053-1068.

Lindenmayer, D. B., R. T. Hobbs, G. E. Likens, C. J. Krebs, and S. C. Banks. 2011. Newly discovered landscape traps produce regime shifts in wet forests. Proceedings of the National Academy of Sciences of the United States of America 108:15887-15891.

Lindenmayer, D. B., M. L. Hunter, P. J. Burton, and P. Gibbons. 2009. Effects of logging on fire regimes in Moist Forests. Conservation Letters 2:271-277.

Lindenmayer, D. B., and W. F. Laurance. 2016. The ecology, distribution, conservation and management of large old trees. Biological Reviews 92(1):1434-1458.

Lindenmayer, D. B., B. G. Mackey, I. C. Mullen, M. A. McCarthy, A. M. Gill, R. B. Cunningham, and C. F. Donnelly. 1999. Factors affecting stand structure in forests: are there climatic and topographic determinants? Forest Ecology and Management 123: $55-63$.

Lindenmayer, D., C. Messier, and C. Sato. 2016. Avoiding ecosystem collapse in managed forest ecosystems. Frontiers in Ecology and the Environment 14:561-568.

Lindenmayer, D. B., and K. Ough. 2006. Salvage logging in the montane ash eucalypt forests of the Central Highlands of Victoria and its potential impacts on biodiversity. Conservation Biology 20:1005-1015.

Lindenmayer, D., S. Thorn, and S. C. Banks. 2017. Please do not disturb ecosystems further. Nature, Ecology and Evolution 1 (31):3.

Lloret, F., and P. H. Zedler. 2009. The effect of forest fire on vegetation. Pages 257-295 in A. Cerda and P. R. Robichaud, editors. Fire Effects on Soil and Restoration Strategies. Science Publishers, Cambridge, UK

Lutze, M. T., R. G. Campbell, and P. C. Fagg. 1999. Development of silviculture in the native State forests of Victoria. Australian Forestry 62:236-244

Ma, L., X. Rao, P. Lu, S. H. Bai, Z. Xu, X. Chen, T. Blumfield, and J. Xie. 2015. Ecophysical and foliar nitrogen concentration responses of understory Acacia spp. and Eucalyptus sp. to prescribed burning. Environmental Science and Pollution Research International 22:1054-10262.

Mackey, B., D. Lindenmayer, M. Gill, M. McCathy, and J. Lindesay. 2002. Wildlife, fire and future climate: a forest ecosystem analysis. CSIRO Publishing, Clayton, Victoria, Australia.

Mason, N. W., C. Frazao, R. P. Buxton, and S. J. Richardson. 2016 Fire form and function: evidence for exaptive flammability in the New Zealand flora. Plant Ecology 217:645-659.
May, B. M., and P. M. Attiwill. 2003. Nitrogen-fixation by Acacia dealbata and changes in soil properties 5 years after mechanical disturbance or slash-burning following timber harvest. Forest Ecology and Management 181:339-355.

McCarthy, M. A., A. M. Gill, and D. B. Lindenmayer. 1999. Fire regimes in mountain ash forest: evidence from forest age structure, extinction models and wildlife habitat. Forest Ecology and Management 124:193-203.

McIntyre, S., and S. Lavorel. 1999. Predicting richness of native, rare and exotic plants in response to habitat and disturbance variables across a variegated landscape. Conservation Biology 8:521-531.

McKenzie, N. J., D. Jacquier, R. Isbell, and K. Brown. 2004. Australian soils and landscapes: an illustrated compendium. CSIRO Publishing, Clayton, Victoria, Australia.

Mueck, S. G., and R. J. Peacock. 1992. Impacts of intensive timber harvesting on the forests of East Gippsland, Victoria. Department of Conservation and Natural Resources, Flora and Fauna Branch, Melbourne, Victoria, Australia.

Noble, I. R., and R. O. Slatyer. 1980. The use of vital attributes to predict successional changes in plant communities subject to recurrent disturbances. Vegetatio 43:5-21.

Odion, D. C., E. J. Frost, J. R. Srittholt, H. Jiang, D. A. Dellasala, and M. A. Moritz. 2004. Patterns of fire severity and forest conditions in the western Klamath Mountains, California. Conservation Biology 18:927-936.

Osazuwa-Peters, O. L., I. Jiménez, B. Oberle, C. A. Chapman, and A. E. Zanne. 2015. Selective logging: Do rates of forest turnover in stems, species composition and functional traits decrease with time since disturbance? A 45 year perspective. Forest Ecology and Management 357:10-21.

Ough, K. 2001. Regeneration of Wet Forest flora a decade after clearfell or wildfire - is there a difference? Australian Journal of Botany 49:649-664.

Ough, K., and A. Murphy. 2004. Decline in tree fern abundance after clearfell harvesting. Forest Ecology and Management 199:153-163.

Ough, K., and J. Ross. 1992. Floristics, fire and clearfelling in wet forests of the Central Highlands. Victorian Government Department of Conservation and Environment, Melbourne, Victoria, Australia.

Parro, K., M. Metslaid, G. Renel, A. Sims, J. A. Stanturf, K. Jõgiste, and K. Köster. 2015. Impact of postfire management on forest regeneration in a managed hemiboreal forest, Estonia. Canadian Journal of Forest Research 45:1192-1197.

Penman, T. D., D. L. Binns, R. J. Shiels, R. M. Allen, and R. P. Kavanagh. 2008. Changes in understory plant species richness following logging and prescribed burning in shrubby dry scleophyll forest of south-eastern Australia. Austral Ecology 33:197-210.

Pickett, S., and P. White. 1985. The ecology of natural disturbance and patch dynamics. Academic Press, New York, New York, USA.

Pulsford, S. A., D. B. Lindenmayer, and D. A. Driscoll. 2016. A succession of theories: purging redundancy from disturbance theory. Biological Reviews 91:148-167.

Rab, M. A. 1996. Soil physical and hydrological properties following logging and slash burning in the Eucalyptus regnans forest of southeastern Australia. Forest Ecology and Management 84:159-176.

Ribeiro-neto, J. D., X. Anan, M. Tabarelli, and I. R. Leal. 2016. Chronic anthropogenic disturbances cause homogenisation of plant and ant communities in the Brazilian Caatinga. Biodiversity and Conservation 25:943-956.

Rodrigo, A., J. Retana, and F. Xavier Picó. 2004. Direct regeneration is not the only response of Mediterranean forests to large fires. Ecology 85:3.

Sato, C., and D. Lindenmayer. 2017. Meeting the global ecosystem collapse challenge. Conservation Letters 11(1):1-7.

Seidl, R., M. J. Schelhaas, W. Rammer, and P. J. Verkerk. $2014 a$. Increasing forest disturbances in Europe and their impact on carbon storage. Nature Climate Change 4:806-810. 
Siedl, R., W. Rammer, and T. A. Spies. 2014b. Disturbance legacies increase the resilience of forest ecosystem structure, composition and functioning. Ecological Applications 24:2063-2077.

Sitters, H., J. Si Stefano, F. Christie, M. Swan, and A. York. 2016 Bird functional diversity decreases with time since disturbance: Does patchy prescribed fire enhance ecosystem function? Ecological Applications, 26:115-127.

Smith, A. L, D. Blair, L. McBurney, S. C. Banks, P. S. Barton, W. D. Blanchard, D. A. Driscoll, A. M. Gill, and D. B. Lindenmayer. 2014. Dominant drivers of seedling establishment in a fire-dependent obligate seeder: Climate or fire regimes? Ecosystems 17:258 270.

Stevens-Rumann, C., and P. Morgan. 2016. Repeated wildfires alter forest recovery of mixed conifer ecosystems. Ecological Applications 26:1842-1853

Taylor, C., M. A. McCarthy, and D. B. Lindenmayer. 2014. Nonlinear effects of stand age on fire severity. Conservation Letters 7:355-370.

Thom, D., and R. Siedl. 2016. Natural disturbance impacts on ecosystem services and biodiversity in temperate and boreal forests. Biological Reviews 91:760-781.

Thompson, J. R., T. A. Spies, and L. M. Ganio. 2007. Reburn severity in managed and unmanaged vegetation in a large wildfire. Proceedings of the National Academy of Sciences USA 104: 10743-10748.

Thorn, S., et al. 2017. Impacts of salvage logging on biodiversity: A meta-analysis. Journal of Applied 55:279-289.

Thuiller, W., S. Lavorel, M. B. Arau'jo, M. T. Sykes, and C. Prentice. 2004. Climate change threats to plant diversity in Europe. Proceedings of the National Academy of Sciences USA 102: $8245-8250$

Turner, J., D. Flinn, M. Lambert, K. Wareing, and S. Murphy. 2011. Management of Victorias publically-owned native forests for wood production: A review of the science underpinning their management. Forest and Wood Products Australia, Melbourne, Victoria, Australia.

VicForests. 2014. Media release: FAP audit records 93 per cent compliance rate and welcomes recommendations on areas for improvement for VicForests. http://www.vicforests.com.au/static/ uploads/files/module-5-release-final-wfgtejmkxhgr.pdf

VicForests. 2016. VicForests procedures: Regulatory handbook 3.0. http://www.vicforests.com.au/static/uploads/files/vicforests-operatingprocedures-regulatory-handbook-v3-0-final-wfmieqhmrzeh. pdf

Victorian State Government. 2004. Vegetation quality assessment manual-guidelines for applying the habitat hectares scoring method —version 1.3. https://www.environment.vic.gov.au/_data/assets/ pdf_file/0023/51809/VQAM-V1_3-Chapters-1-11.pdf; http://www. dse.vic.gov.au/_data/assets/pdf_file/0011/99227/VQAM_V1_3 Appendix_1-6.pdf

Victorian State Government. 2014. Victoria's State of the forests report 2013. https://www.forestsandreserves.vic.gov.au/_data/assets/ pdf_file/0019/52705/VIC_SFR2013_lowres.pdf

Walker, B. 1995. Conserving biological diversity through ecosystem resilience. Conservation Biology 9:747-752.

Walsh, N. G., and T. J. Entwisle. 1994. Flora of Victoria: Volume 2. Ferns and allied plants, conifers and monocotyledons. Inkata Press, Melbourne, Victoria, Australia.

Walsh, N. G., and T. J. Entwisle. 1996. Flora of Victoria: Volume 3. Dicotyledons, Winteraceae to Myrtaceae. Inkata Press, Melbourne, Victoria, Australia.

Walsh, N. G., and T. J. Entwisle. 1997. Flora of Victoria: Volume 4. Dicotyledons continued, Olacaceae to Asteraceae. Inkata Press, Melbourne, Victoria, Australia.

Westerling, A. L., and B. P. Bryant. 2008. Climate change and wildfire in California. Climate Change 87:231-249.

Wienk, C. L., and G. R. McPherson. 2004. Evaluating the role of cutting treatments, fire and soil seed banks in an experimental framework in pondersora pine forests of the Black Hills. South Dakota. Forest Ecology and Management 192:375-393.

Wood, S. W., Q. Hua, K. J. Allen, and D. M. J. S. Bowman. 2010. Age and growth of a fire prone Tasmanian temperate old-growth forest stand dominated by Eucalyptus regnans, the world's tallest angiosperm. Forest Ecology and Management 260:438-447.

\title{
SUPPORTING INFORMATION
}

Additional supporting information may be found online at: http://onlinelibrary.wiley.com/doi/10.1002/eap.1693/full

\author{
Data Availability
}

Data available from the Dryad Digital Repository: https://doi.org/10.5061/dryad.18913 